\title{
3D-Printed Carbon Fiber Reinforced Polymer Composites: A Systematic Review
}

\author{
Seyed Hamid Reza Sanei $1, *\left(\mathbb{D}\right.$ and Diana Popescu ${ }^{2}$ (D) \\ 1 Department of Mechanical Engineering, Penn State University, Erie, PA 16510, USA \\ 2 Department of Robotics and Production Systems, University Politehnica of Bucharest, \\ 060042 Bucharest, Romania; diana@mix.mmi.pub.ro \\ * Correspondence: sus810@psu.edu
}

Received: 10 June 2020; Accepted: 22 July 2020; Published: 24 July 2020

check for updates

\begin{abstract}
Fiber reinforced composites offer exceptional directional mechanical properties, and combining their advantages with the capability of 3D printing has resulted in many innovative research fronts. This review aims to summarize the methods and findings of research conducted on 3D-printed carbon fiber reinforced composites. The review is focused on commercially available printers and filaments, as their results are reproducible and the findings can be applied to functional parts. As the process parameters can be readily changed in preparation of a 3D-printed part, it has been the focus of many studies. In addition to typical composite driving factors such as fiber orientation, fiber volume fraction and stacking sequence, printing parameters such as infill density, infill pattern, nozzle speed, layer thickness, built orientation, nozzle and bed temperatures have shown to influence mechanical properties. Due to the unique advantages of 3D printing, in addition to conventional unidirectional fiber orientation, concentric fiber rings have been used to optimize the mechanical performance of a part. This review surveys the literature in 3D printing of chopped and continuous carbon fiber composites to provide a reference for the state-of-the-art efforts, existing limitations and new research frontiers.
\end{abstract}

Keywords: 3D printing; reinforced printing; process parameters; mechanical properties; short fibers; continuous fibers

\section{Introduction}

Three-dimensional printing (3DP)—also referred to as additive manufacturing—has enabled the manufacturing of complex geometries to the final shape without any need for special tools, devices or jigs. While the 3DP of polymers has received a lot attention in the past two decades, the printing of composite materials is an emerging area of research, with only one commercially available printer type for manufacturing continuous fiber composites and only a few under development.

3DP can also be a challenging process, as usually a trial and error process is employed for identifying the combination of factors (material, printer, process parameters, post-processing) that can produce the required outcome. A method to reduce the number of iterations associated to this experimental approach is to take decisions based on the available information from the previous research studies carried out in this field. This information should be used in context, i.e., being aware of the complex dependences between the process factors and their impact on the prints' mechanical performance or quality. Thus, there is a need for scientific literature addressing the 3DP process from different perspectives, to enhance understanding and knowledge and to offer guidance in the trade-offs inherent in the development process of 3D-printed functional parts.

The purpose of this review is to offer a comprehensive summary of work done on reporting the mechanical properties obtained from 3DP of carbon fiber reinforced composites. The review aims 
to answer three main research questions. The research questions and corresponding objectives are presented in Figure 1.

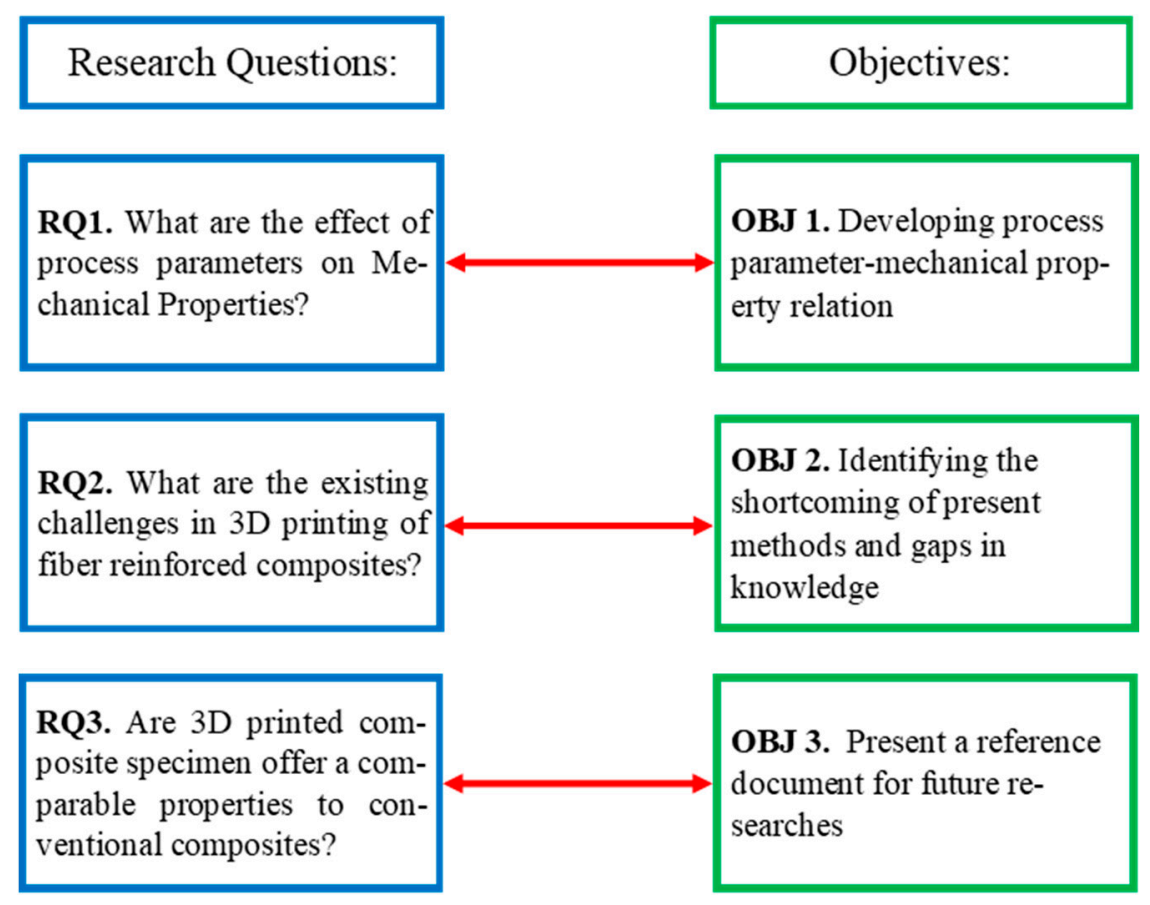

Figure 1. Research questions and corresponding objectives.

The review is organized as follows. The following part of this section discusses the 3DP process of fiber reinforced composites based on a classification according to the type of fiber, matrix, 3D printer and process specifications. It also lists the main variables affecting the prints mechanical properties and the research directions inferred from the analyzed literature. The materials and methods used for systematically identifying, selecting and analyzing the studies included in this review are presented in Section 2. Section 3 summarizes the results from different viewpoints, categorizes the information and discusses the mechanical performances in relationship to process parameters such as infill pattern, fiber orientation, volume fraction and stacking sequence, specimen size effect, etc. Aspects specific to 3DP fiber reinforced composites like the specimens design and tabs, starting-ending points of fibers, defects and information on microstructure are also addressed. Section 4 concludes the paper and presents the knowledge gap in the field and provides several suggestions for further research directions.

\section{D Printing Fiber Reinforced Polymer Composites}

Fused deposition modeling (FDM) is currently the most used additive process for manufacturing parts for fiber reinforced polymers [1,2]. The paradigm is ranging from prototyping to functional parts that require high mechanical performances. The first reference found in literature dates before 2000 [3] while the majority of the studies were conducted within the last five years. However, based on the literature review, the research work in this field is still at the beginning, and many aspects of composite 3DP are remaining to be clarified, investigated further and in more depth, while the results should be more thoroughly reported.

The following research directions could be inferred from the reviewed studies:

(1) Improving the mechanical properties of 3DP fiber reinforced composites by:

(a) Analyzing the impact of process parameters on the mechanical behavior of specimens to optimize a certain property or group of properties [4-9]; 
(b) Analyzing the modes of failure to better understand the microstructural failure mechanisms of 3D printed fiber reinforced specimens $[1,10,11]$;

(c) Developing fiber and matrix filaments and novel printers to achieve enhanced mechanical properties [12-14];

(2) Developing or evaluating analytical/numerical models for predicting the mechanical properties of 3DP fiber based composites [8,11,15-17];

(3) Applying the current knowledge to functional parts [7].

Efforts dedicated to 3DP of composite materials can be classified based on the choice of material, the fiber/matrix impregnation method and the hardware used. Figure 2 shows a classification chart used in this study. While studies presented in literature are addressing all these topics, this review is focused on a synthesis of the data derived from research conducted using commercially available materials and printers as they are available to those interested in applying the reviewed knowledge to the 3DP of functional parts. Despite many interesting and promising results, in-house materials and developed/modified 3D printers are still in the prototyping phase. Therefore, they are only available to the original developers and the results are not yet reproducible outside the respective labs.

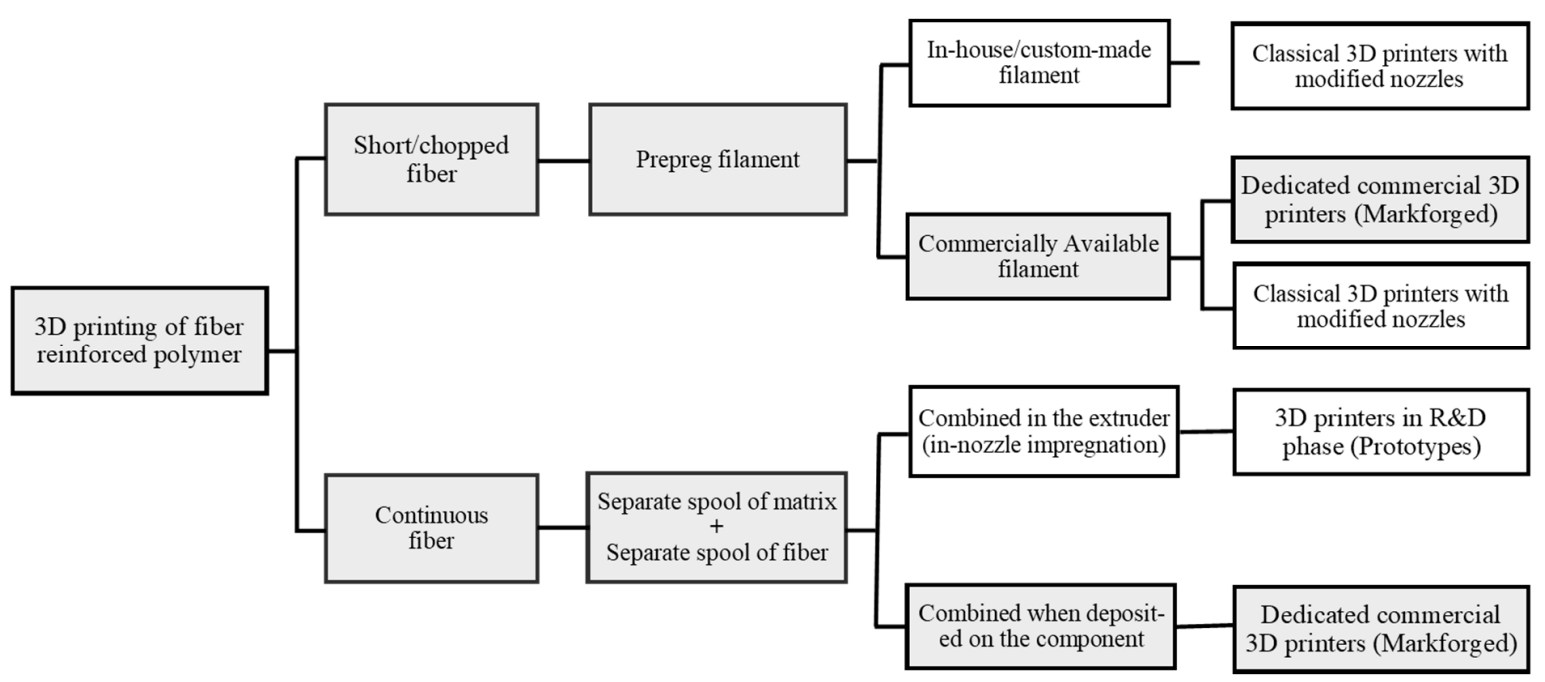

Figure 2. Classification of 3D-printed fiber reinforced polymer manufacturing process (highlighted $=$ addressed in this review).

This systematic review comes to supplement and update the information presented by other surveys in the field $[1,2,10,18]$, tackling diverse aspects linked to 3D-printed carbon reinforced polymer composites with short and continuous fibers, such as print process parameters, specimens design, specimens' mechanical properties and microstructural analysis.

Similar to conventional composites, the mechanical behavior of 3D-printed composites is function of constituents' properties, morphology of the reinforcement, adhesion between the constituents, reinforcement volume fraction and manufacturing process. For the case of 3DP, the manufacturing process can be controlled with the choice of print parameters as seen in Figure 3 [19]. It is their combination that ensures the conformity of 3D-printed parts to the functional requirements, while the large variability of these factors makes the study of the dependency between 3DP parameters and mechanical properties a rich research subject. The majority of the parameters presented in Figure 3 are common to the material extrusion process regardless of the type of the filament material. However, there are also parameters specific to the fiber-reinforced composites such as fiber orientation and fiber volume fraction. 


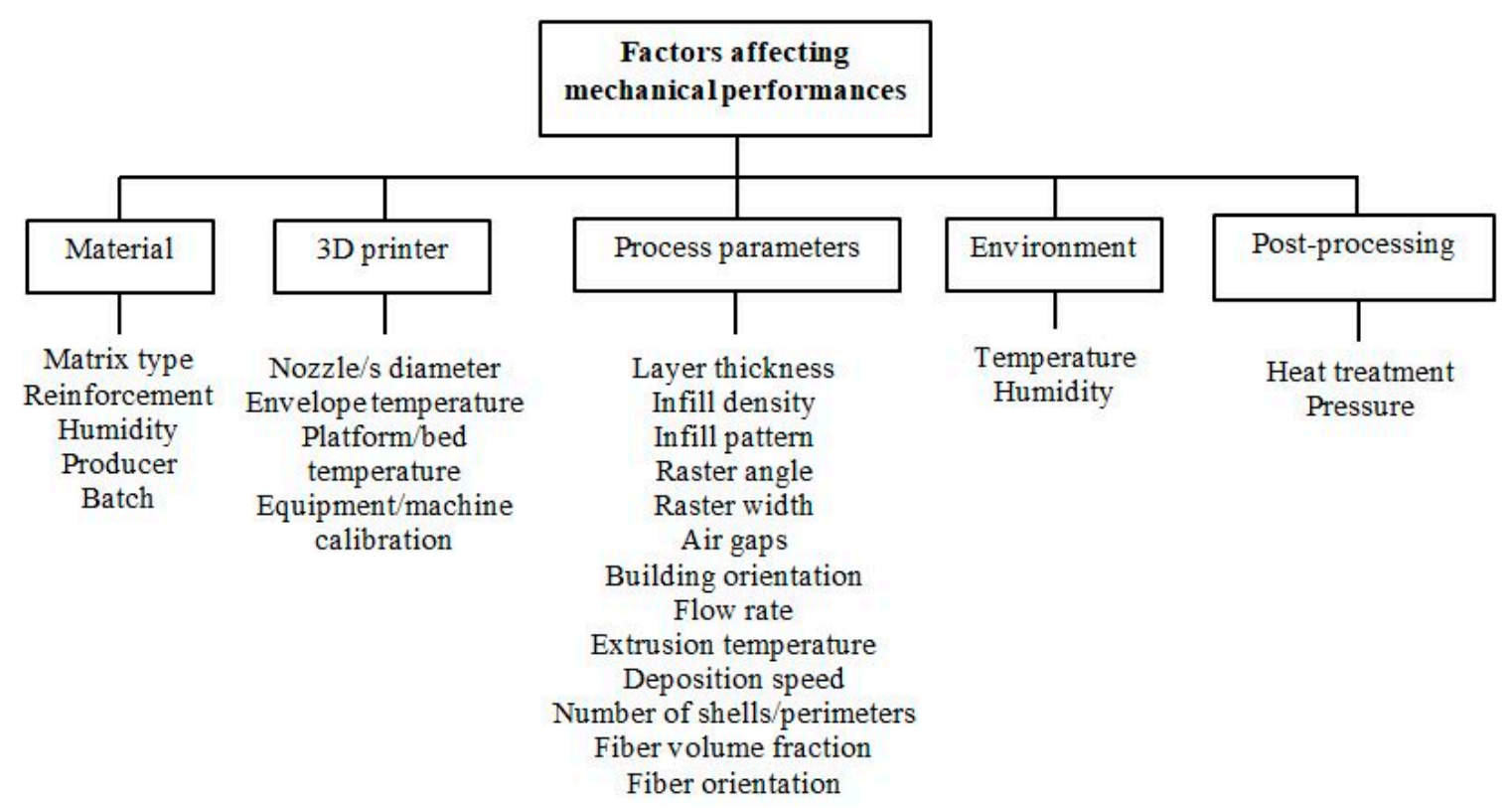

Figure 3. Factors influencing mechanical performances of 3DP specimen.

In different extent, 3D printers (through the associated slicing software) allow the setting of process parameters, low-cost general use machines usually offering more options in this sense, while for Markforged printers (Markforged Inc., Watertown, MA, USA) less settings are controlled by the user. The deposition temperature, for instance, is not adjustable, nor is the extrusion speed and nozzle diameter. The sequence in which matrix material and reinforcements are stacked is also impacting the mechanical properties of the print. Markforged 3D printers limit the user input related to the design of the stacking, by mandatory building top and bottom layers of matrix material, and the fiber cannot be deposited for the surrounding shell layers either. Leaving asides these settings restrictions, there are still plenty of parameters to tune. Therefore, their impact on mechanical performances of printed specimen can be studied by means of experimental testing. However, extending the experimental results to complex geometries is not straightforward.

There are several major challenges related to 3DP of composites. Some of which are 3DP process dependent regardless of the reinforcement presence, such as intrinsic anisotropy, voids, and complex dependences of the mechanical properties and parts' quality on a large series of process parameters. Other challenges are specific to the fiber inclusion such as fiber/matrix consolidation (interface quality), fiber stacking, volume fractions and orientation to achieve the desired outcome.

\section{Data and Method}

PRISMA guidelines (Preferred Reporting Items for Systematic Reviews and Meta-Analyses) were followed for conducting this review [20].

\subsection{Search Strategy}

Scopus, Web of Science, Springer and ScienceDirect electronic databases were searched in April 2020 using combinations of the following searching terms: "3D printing, "Fused Deposition Modeling", "Additive Manufacturing", "Carbon fiber", "mechanical properties". Only studies in English language were considered within the timeframe of January 2001 to March 2020. The search also identified several reviews on the topic. Reviews were used as a source for finding other relevant studies along the references of full read studies (snowballing approach). 


\subsection{Eligibility Criteria}

Articles indexed in the searched databases were included. Studies must have investigated the mechanical properties of 3DP composites manufactured with short or continuous carbon fibers (CF) with any matrix polymers (PLA - polylactic acid, ABS - acrylonitrile butadiene styrene, nylon, PETG—-polyethylene terephthalate glycol, PEEK—polyether ether ketone, PP—polypropylene, PC-polycaprolactone, etc.). The exclusion criteria applied to studies focused solely on the development or modification of 3D printers, extruders or materials. The rationale for the exclusion of such studies was elaborated in Section 2.

\subsection{Records Management, Data Quality and Data Extraction}

Figure 4 shows the flow diagram of the search and selection process. The search strategy was independently performed by the authors using the aforementioned keywords. Using Mendeley reference management software, duplicates were eliminated and the studies' titles and abstracts were screened based on the pre-established eligibility criteria. The two lists were then compared and the discrepancies were discussed. As a result, a short list of 41 papers was kept for independent full-text read. The data extraction included items study design, CF composite (short/continuous fiber and matrix material), 3D printer, process parameters, specimens' type/standard, investigated mechanical properties and outcomes. A narrative description of the included studies was carried out for analyzing the reported mechanical properties (tensile, flexural, compressive, impact, creep, fatigue, in-plane shear and indentation) of 3DP CF-based composites and their modes of failures, the specific process parameter settings and their impact on mechanical behavior. Specimens' design was also a subject of discussion in this review as the reported mechanical properties are influenced by specimens' shape and dimensions.
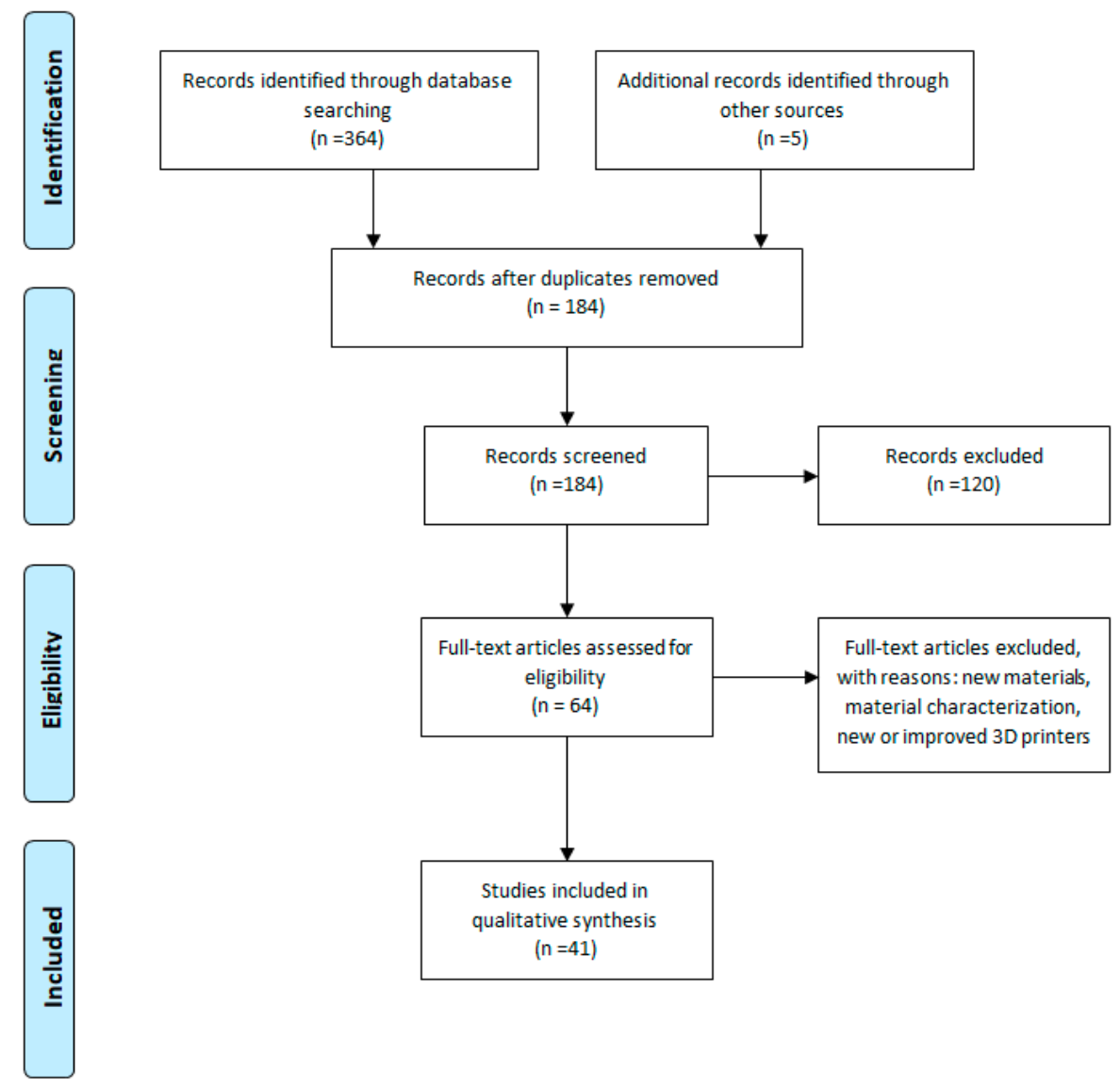

Figure 4. Search and selection process flow diagram. 


\section{Results and Discussions}

To get a broad perspective over the filed, a range of statistical indicators are presented in terms of number of studies published per year (Figure 5), number of studies for different mechanical properties with the observation that many studies are addressing more than one mechanical property (Figure 6) and number of studies on short vs. continuous fibers (Figure 7). A detailed classification of synthetic information on the purpose of each research, studied process parameters, specimen geometry and standards are presented in Tables 1 and 2.

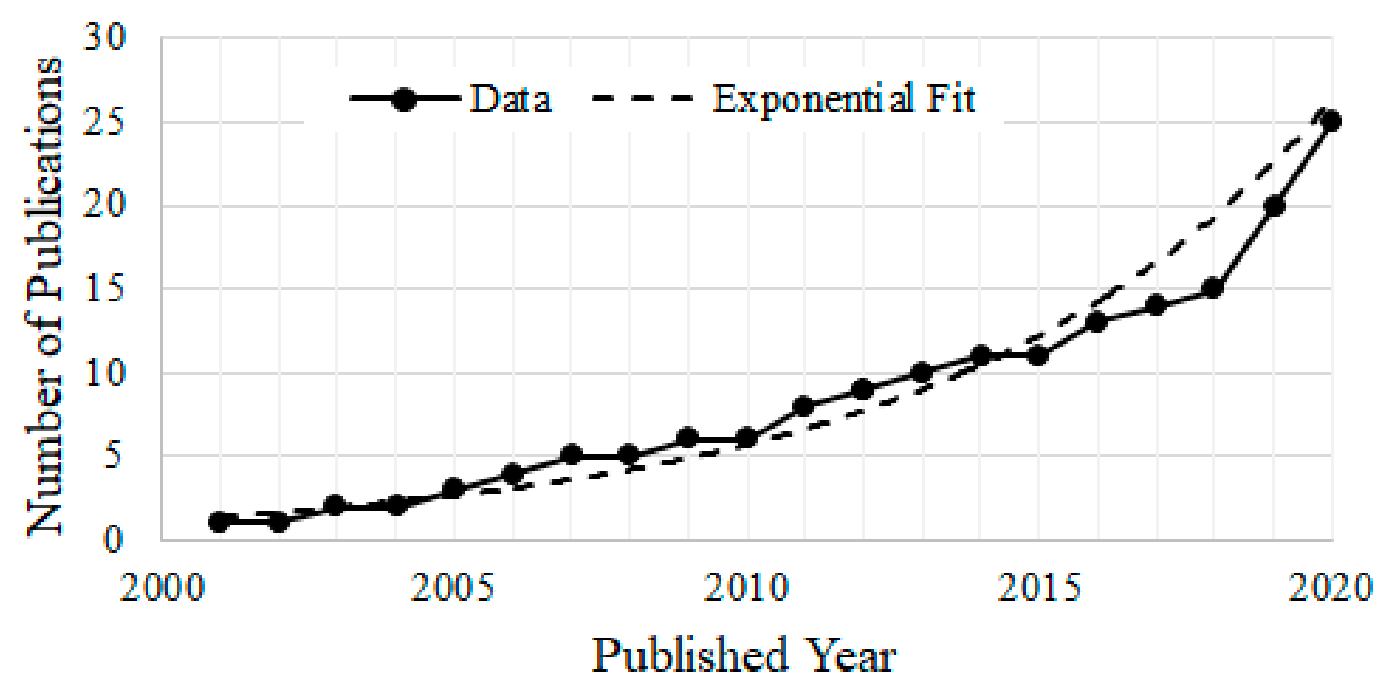

Figure 5. Number of published papers on 3D-printed carbon fiber (CF) reinforced composites over the last two decades.

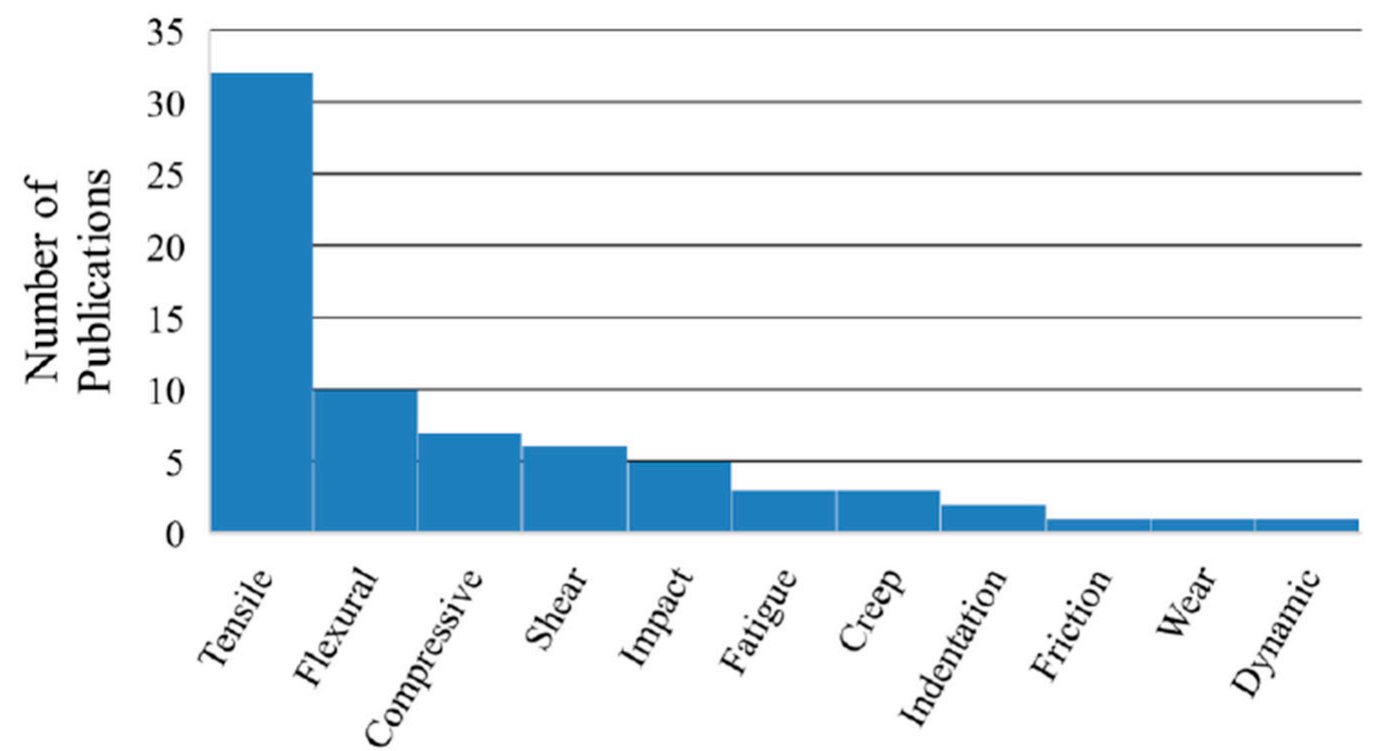

Mechanical Properties

Figure 6. Number of publications on studied mechanical properties, papers studying more than one mechanical property is counted in both categories. 
(A)

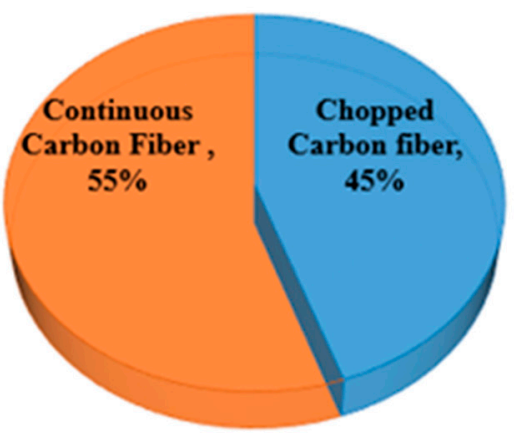

(B)

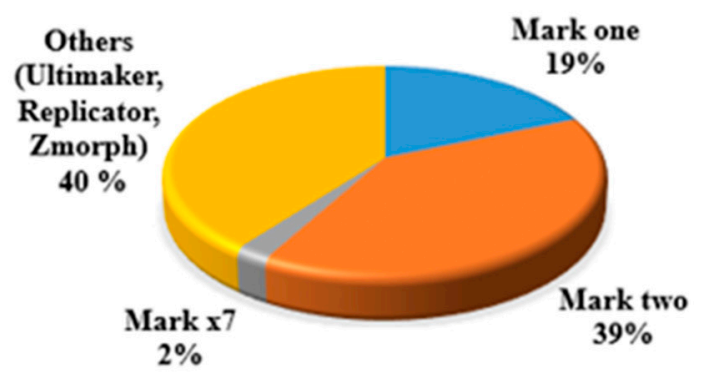

Figure 7. (A) Choice of reinforcement among 3D printing composite studies; (B) printers used in manufacturing 3D-printed CF composites.

Table 1. Effect of print process parameters on mechanical properties of fiber reinforced composites.

\begin{tabular}{cc}
\hline Process Parameter & Published Research \\
\hline Fiber orientation (unidirectional, concentric) & {$[4,10,21-27]$} \\
Fiber volume fraction & {$[4,6-8,11,21,24,26,27]$} \\
Stacking sequence (Angle ply, cross-ply, balanced, symmetric) & {$[4,6,7,28,29]$} \\
Matrix infill pattern (triangular, rectangular, hexagonal) & {$[8,21,23,30-32]$} \\
Infill density & {$[8,30,32,33]$} \\
Number of concentric fiber rings & {$[8,22,26,27,34]$} \\
Raster angle & {$[35-38]$} \\
Layer thickness & {$[6,7,17,36,39]$} \\
Build orientation & {$[6,7,30,31,37,39]$} \\
Platform temperature & {$[32]$} \\
Printing temperature & {$[38,39]$} \\
Deposition speed & {$[39]$} \\
Annealing temperature & {$[40]$} \\
\hline
\end{tabular}

\subsection{D Printing Carbon Reinforced Polymers}

Short CF reinforced PLA, PETG, ABS, etc. filaments are used as feedstock for low-cost general use 3D printers with hardened steel nozzles. For these materials, the 3DP process is similar to 3DP of non-reinforced polymers, therefore no further details are provided in this review. However, as shown in Figure 2, there are two specific 3DP processes for continuous fiber reinforced composites presented here: continuous fiber fabrication (CFF, Markforged Inc.) and in-nozzle impregnation. 
Table 2. Summarizing the research objective, material and methods used in studies focused on mechanical properties of 3D-printed CF composites.

\begin{tabular}{|c|c|c|c|c|c|c|c|}
\hline Study & Research Objective & Analyzed Parameters & Material & $\begin{array}{l}\text { Short/Continuous } \\
\text { Fiber }\end{array}$ & 3D Printer & Studied Mech. Prop & Specimen Design \\
\hline Abdullah et al. [33] & $\begin{array}{c}\text { Mechanical properties } \\
\text { evaluation }\end{array}$ & Infill density & $\mathrm{ABS} / 15 \% \mathrm{CF}$ & Short & Makerbot Replicator 2 & Compressive & ASTM D695 \\
\hline Akasheh et al. [41] & $\begin{array}{l}\text { Reinforcement schemes for } \\
\text { improving fracture } \\
\text { toughness }\end{array}$ & Reinforcement pattern & Onyx, Onyx/CF & Both & MarkTwo & $\begin{array}{l}\text { Tensile, residual stiffness, } \\
\text { fracture behavior }\end{array}$ & ASTM D638, ASTM D3039 \\
\hline Al Abadi et al. [15] & $\begin{array}{l}\text { Evaluation of elastic } \\
\text { properties of } \\
\text { fiber-reinforced polymers, } \\
\text { prediction model based on } \\
\text { volume average stress }\end{array}$ & N/A & $\begin{array}{l}\text { Nylon/CF, glass, } \\
\text { Kevlar }\end{array}$ & Continuous & MarkOne & Tensile & ASTM D303 \\
\hline Araya-Calvo et al. [4] & $\begin{array}{l}\text { Parameters optimization for } \\
\text { improving mechanical } \\
\text { properties }\end{array}$ & $\begin{array}{l}\text { Reinforcement pattern, fiber } \\
\text { orientation, build } \\
\text { orientation, fiber volume } \\
\text { content, stacking sequence }\end{array}$ & Onyx/CF & Continuous & MarkTwo & Compressive, flexural & $\begin{array}{l}\text { ASTM D695, } \\
\text { ASTM D790 }\end{array}$ \\
\hline Bakis et al. [35] & Anisotropy evaluation & Raster angle, fiber volume & $\mathrm{PLA} / \mathrm{C}_{\mathrm{w}}$ & Short & MendelMax 3 & Tensile & Custom rectangular specimer \\
\hline Blok et al. [5] & $\begin{array}{l}\text { Mechanical properties } \\
\text { comparison of short and } \\
\text { continuous CF composites }\end{array}$ & N/A & $\begin{array}{c}27 \% \text { Nylon/CF, } \\
\text { Nylon } / 6 \text { wt } \% \text { short CF }\end{array}$ & Both & MarkOne, Lulzbot TAZ & Tensile, flexural, in-plane shear & $\begin{array}{l}\text { ASTM D638, } \\
\text { ASTM D7264, } \\
\text { ASTM D3518 }\end{array}$ \\
\hline Caminero et al. [6] & $\begin{array}{l}\text { Process parameter influence } \\
\text { on impact resistance }\end{array}$ & $\begin{array}{c}\text { Layer thickness, fiber } \\
\text { volume content, build } \\
\text { orientation, stacking } \\
\text { sequence }\end{array}$ & Nylon/CF, GF, KF & Continuous & MarkTwo & Impact & ASTM D6110 \\
\hline Chacon et al. [7] & $\begin{array}{l}\text { Process parameter influence } \\
\text { on mechanical properties }\end{array}$ & $\begin{array}{c}\text { Layer thickness, fiber } \\
\text { volume content, build } \\
\text { orientation, stacking } \\
\text { sequence }\end{array}$ & Nylon/CF, GF, KF & Continuous & MarkTwo & Tensile, flexural & $\begin{array}{l}\text { ASTM D3039, } \\
\text { ASTM D790 }\end{array}$ \\
\hline Dickson et al. [24] & $\begin{array}{l}\text { Process parameter influence } \\
\text { on mechanical properties }\end{array}$ & $\begin{array}{c}\text { Fiber orientation, fiber } \\
\text { volume content, fiber type }\end{array}$ & Nylon/CF, GF, KF & Continuous & MarkOne & Tensile, flexural & $\begin{array}{l}\text { ASTM D3039, } \\
\text { ASTM D790 }\end{array}$ \\
\hline Ding et al. [39] & $\begin{array}{l}\text { Process parameter influence } \\
\text { on mechanical properties }\end{array}$ & $\begin{array}{l}\text { Printing temperature, } \\
\text { printing speed, build } \\
\text { orientation, layer thickness }\end{array}$ & $\mathrm{PLA} / 20 \% \mathrm{CF}$ & Short & U-print machine A8 & Tensile, impact, friction, wear & $\begin{array}{c}\text { ASTM D638, } \\
\text { Rectangular unnotched } \\
60 \mathrm{~mm} \times 9.5 \mathrm{~mm} \times 3.5 \mathrm{~mm} \\
\end{array}$ \\
\hline Dutra et al. [25] & $\begin{array}{c}\text { Mechanical properties } \\
\text { investigation, prediction } \\
\text { model based on asymptotic } \\
\text { homogenization technique }\end{array}$ & Fiber orientation & Nylon/CF & Continuous & MarkOne & $\begin{array}{l}\text { Tensile (longitudinal } \\
\text { transverse), compression } \\
\text { (longitudinal), in-plane shear }\end{array}$ & $\begin{array}{l}\text { ASTM D3039, } \\
\text { ASTM D638, } \\
\text { ASTM D6641, } \\
\text { ASTM D3518 } \\
\end{array}$ \\
\hline Ferreira et al. [16] & $\begin{array}{c}\text { Mechanical properties } \\
\text { evaluation }\end{array}$ & Raster angle & $\mathrm{PLA} / 15 \%$ CF & Short & $\begin{array}{l}\text { BQ Prusa270i3 } \\
\text { Hephesto }\end{array}$ & Tensile, in-plane shear & $\begin{array}{c}\text { ASTM D638 } \\
\text { ASTM D3518 }\end{array}$ \\
\hline Ferreira et al. [42] & $\begin{array}{l}\text { Mechanical properties } \\
\text { evaluation }\end{array}$ & N/A & $\mathrm{PETG} / 20 \% \mathrm{CF}$ & Short & Tronxy X5 & Tensile, flexural & $\begin{array}{l}\text { ISO-527, } \\
\text { ISO-178 }\end{array}$ \\
\hline
\end{tabular}


Table 2. Cont.

\begin{tabular}{|c|c|c|c|c|c|c|c|}
\hline Study & Research Objective & Analyzed Parameters & Material & $\begin{array}{c}\text { Short/Continuous } \\
\text { Fiber }\end{array}$ & 3D Printer & Studied Mech. Prop & Specimen Design \\
\hline Ghebretinsae et al. [43] & $\begin{array}{l}\text { Mechanical properties } \\
\text { evaluation }\end{array}$ & N/A & Onyx/CF & Continuous & MarkTwo & Tensile, flexural & $\begin{array}{c}\text { ASTM D3039, } \\
(250 \mathrm{~mm} \times 15 \mathrm{~mm} \times 1.75 \mathrm{~mm}) \\
\text { ASTM D7264 }\end{array}$ \\
\hline Giannakis et al. [44] & $\begin{array}{l}\text { Mechanical properties } \\
\text { evaluation (PLA, Nylon, } \\
\text { Nylon/CF comparison) }\end{array}$ & N/A & Nylon/CF, PLA, Nylon & Continuous & BCN3D, MarkTwo & Tensile, fatigue & $\begin{array}{l}\text { ASTM D3039, } \\
\text { custom specimens }\end{array}$ \\
\hline Goh et al. [45] & $\begin{array}{l}\text { Mechanical properties } \\
\text { evaluation }\end{array}$ & N/A & Nylon $/ 41 \%$ CF & Continuous & MarkOne & $\begin{array}{l}\text { Tensile, flexural, quasi-static } \\
\text { indentation }\end{array}$ & $\begin{array}{l}\text { ASTM D3039, } \\
\text { ASTM D790, } \\
\text { ASTM D6264 } \\
\end{array}$ \\
\hline $\begin{array}{l}\text { Gonzalez-Estrada et al. } \\
\text { [21] }\end{array}$ & $\begin{array}{l}\text { Process parameter influence } \\
\text { on mechanical properties }\end{array}$ & $\begin{array}{l}\text { Fiber orientation, fiber } \\
\text { volume content, } \\
\text { infill pattern, }\end{array}$ & Nylon/CF, GF, KF & Continuous & MarkTwo & Tensile & ASTM D638, type IV \\
\hline Imeri et al. [22] & $\begin{array}{l}\text { Process parameter influence } \\
\text { on mechanical properties }\end{array}$ & $\begin{array}{c}\text { Fiber orientation, infill } \\
\text { pattern, fiber type, number } \\
\text { of rings }\end{array}$ & Nylon/CF, GF, KF & Continuous & MarkTwo & Fatigue & ASTM E606M \\
\hline Iraqi et al. [46] & $\begin{array}{l}\text { Mechanical properties } \\
\text { evaluation }\end{array}$ & N/A & Onyx/CF & Continuous & MarkTwo & $\begin{array}{l}\text { Tensile, in-plane shear, } \\
\text { interlaminar shear }\end{array}$ & $\begin{array}{l}\text { ASTM D3039, } \\
\text { ASTM D518, } \\
\text { ASTM D2344 }\end{array}$ \\
\hline Ivey et al. [40] & $\begin{array}{c}\text { Mechanical properties } \\
\text { evaluation, annealing } \\
\text { temperature effect on tensile } \\
\text { properties }\end{array}$ & Annealing temperature & PLA $/ 15 \%$ CF & Short & RoVa3D 5 & Tensile & ASTM D638-14 type V \\
\hline Jiang et al. [47] & $\begin{array}{l}\text { Anisotropy evaluation, } \\
\text { materials comparison }\end{array}$ & Raster angle & $\begin{array}{c}\text { PLA/CF, ABS/CF, } \\
\text { PETG/CF, } \\
\text { Amphora/CF }\end{array}$ & Short & Makerbot Replicator 2x & Tensile & ASTMD638 type I \\
\hline Justo et al. [48] & $\begin{array}{l}\text { Mechanical properties } \\
\text { evaluation }\end{array}$ & N/A & Nylon/CF & Continuous & MarkOne & $\begin{array}{l}\text { Tensile, compressive, in-plane } \\
\text { shear }\end{array}$ & $\begin{array}{l}\text { ASTM D3039, } \\
\text { ASTM D695-02a, } \\
\text { ASTM D3518 }\end{array}$ \\
\hline Mansour et al. [49] & $\begin{array}{l}\text { Mechanical and dynamic } \\
\text { properties evaluation }\end{array}$ & N/A & PETG/20\% CF & Short & Zmorph SX FDM & $\begin{array}{c}\text { Compressive, cyclic } \\
\text { compressive, nanoindentation }\end{array}$ & Custom cylindrical specimens \\
\hline $\begin{array}{c}\text { Mohammadizadeh et al. } \\
\text { [34] }\end{array}$ & Creep investigations & $\mathrm{N} / \mathrm{A}$ & Nylon/CF, GF, KF & Continuous & MarkTwo & $\begin{array}{l}\text { Creep, dynamic thermal } \\
\text { analysis }\end{array}$ & ASTM D-2990-17 \\
\hline $\begin{array}{l}\text { Mohammadizadeh et al. } \\
{[10]}\end{array}$ & Structural analysis & $\begin{array}{c}\text { Fiber type, fiber orientation, } \\
\text { number of rings, } \\
\text { temperature }\end{array}$ & Nylon/CF, GF, KF & Continuous & MarkTwo & Tensile, fatigue, creep & $\begin{array}{l}\text { ASTM D638-14 type I ASTM } \\
\text { E606M, ATSM D2990-17 }\end{array}$ \\
\hline $\begin{array}{l}\text { Naranjo-Losada et al. } \\
\text { [8] }\end{array}$ & $\begin{array}{l}\text { Mechanical properties } \\
\text { evaluation, predictive } \\
\text { model based on RoM }\end{array}$ & $\begin{array}{l}\text { Infill density, infill pattern, } \\
\text { fiber volume content, } \\
\text { reinforcement pattern, } \\
\text { number or rings }\end{array}$ & PA6, Onyx, Nylon/CF & Both & MarkTwo & Tensile & ASTM D638-14 Type I \\
\hline
\end{tabular}


Table 2. Cont

\begin{tabular}{|c|c|c|c|c|c|c|c|}
\hline Study & Research Objective & Analyzed Parameters & Material & $\begin{array}{c}\text { Short/Continuous } \\
\text { Fiber }\end{array}$ & 3D Printer & Studied Mech. Prop & Specimen Design \\
\hline Oztan et al. [11] & $\begin{array}{l}\text { Mechanical properties } \\
\text { evaluation, predictive } \\
\text { model based on RoM }\end{array}$ & N/A & PLA, CF, KF, Nylon & Continuous & $\begin{array}{l}\text { MarkOne, } \\
\text { Ultimaker } 2\end{array}$ & Tensile & ASTM D3039 \\
\hline Patterson et al. [50] & $\begin{array}{l}\text { Process parameter influence } \\
\text { on mechanical properties }\end{array}$ & $\begin{array}{l}\text { Raster angle, print } \\
\text { orientation }\end{array}$ & $\begin{array}{c}\text { ABS, PLA, HIPS, } \\
\text { PETG, PC, Nylon, } \\
\text { AlPLA, WPLA, } \\
\text { HTPLA, PLA } 15 \% \text { CF }\end{array}$ & Short & Prusa & Impact & ASTM D256 type E \\
\hline Pyl et al. [29] & $\begin{array}{l}\text { Process parameter influence } \\
\text { on mechanical properties }\end{array}$ & $\begin{array}{c}\text { Different specimens design, } \\
\text { fiber orientation, stacking } \\
\text { sequence }\end{array}$ & Nylon/CF & Continuous & MarkTwo & Tensile, in-plane shear & $\begin{array}{c}\text { ASTM D638-14 Type I, ASTM } \\
\text { D638 type IV, ASTM D638 } \\
\text { type IV modified, ASTM } \\
\text { D3039 }\end{array}$ \\
\hline Rao et al. [38] & $\begin{array}{l}\text { Mechanical properties } \\
\text { evaluation }\end{array}$ & $\begin{array}{l}\text { Layer thickness, extrusion } \\
\text { temperature, infill pattern }\end{array}$ & PLA/CF & Short & Ultimaker & Tensile & ASTMD638 type I \\
\hline Sanei et al. [51] & $\begin{array}{l}\text { Mechanical properties } \\
\text { evaluation }\end{array}$ & Fiber orientation & Onyx & Continuous & Markedforged X7 & Tensile & ASTM D3039 \\
\hline Sarvesani et al. [26] & $\begin{array}{l}\text { Mechanical properties and } \\
\text { electrical conductivity } \\
\text { evaluation }\end{array}$ & $\begin{array}{l}\text { Fiber volume fraction, } \\
\text { number of rings }\end{array}$ & Nylon/CF & Continuous & MarkTwo & Tensile & $\begin{array}{c}\text { ASTM D638-14 Type I, ASTM } \\
\text { D638-14 Type IV, ASTM } \\
\text { D3039 }\end{array}$ \\
\hline Somirredy et al. [17] & $\begin{array}{l}\text { Mechanical properties } \\
\text { evaluation, predictive } \\
\text { model based on } \\
\text { laminate theory }\end{array}$ & Raster angle, layer thickness & $\mathrm{ABS} / \mathrm{CF}$ & Short & Ultimaker & $\begin{array}{c}\text { Tensile, interlaminar fracture } \\
\text { toughness }\end{array}$ & ASTM D303, ASTM D5528 \\
\hline Tezel et al. [36] & $\begin{array}{l}\text { Process parameter influence } \\
\text { on mechanical properties }\end{array}$ & Raster angle, layer thickness & PLA $/ 15 \%$ CF & Short & Zmorph & Creep & ASTM D638 Type IV \\
\hline Todoroki et al. [23] & $\begin{array}{l}\text { Process parameter influence } \\
\text { on mechanical properties }\end{array}$ & Fiber orientation & Nylon/CF & Continuous & MarkTwo & Tensile & $\begin{array}{l}\text { Custom specimens with no } \\
\text { surface layers }\end{array}$ \\
\hline van der Klift [28] & $\begin{array}{l}\text { MarkOne 3D printer } \\
\text { benchmark }\end{array}$ & Stacking sequence, & Nylon/34.5\% CF & Continuous & MarkOne & Tensile & JIS K 7073 \\
\hline de Toro et al. [32] & $\begin{array}{l}\text { Mechanical properties } \\
\text { evaluation, comparison 3DP } \\
\text { and injection molding }\end{array}$ & Infill pattern, infill density & PA6/ $20 \mathrm{wt} \%$ CF & Short & Ultimaker 2 & Tensile, flexural, compressive & Custom specimens \\
\hline Wang et al. [37] & $\begin{array}{l}\text { Mechanical properties } \\
\text { evaluation }\end{array}$ & $\begin{array}{l}\text { Raster orientation, build } \\
\text { orientation }\end{array}$ & $\begin{array}{c}\text { ABS, ABS/CF, ABS/KF, } \\
\text { ABS/CF/KF }\end{array}$ & Short & Raise3D N2 & Flexural & $\begin{array}{c}\text { Rectangular custom } \\
\text { specimens }\end{array}$ \\
\hline Yasa et al. [30] & $\begin{array}{c}\text { Mechanical properties and } \\
\text { dimensional accuracy } \\
\text { evaluation }\end{array}$ & $\begin{array}{l}\text { Infill density, build } \\
\text { orientation, infill pattern }\end{array}$ & Onyx & Short & MarkTwo & Tensile & ASTM D638 \\
\hline Yasa et al. [31] & $\begin{array}{l}\text { Mechanical properties } \\
\text { evaluation, comparison to } \\
\text { injection molding }\end{array}$ & $\begin{array}{l}\text { Infill density, build } \\
\text { orientation, fill pattern }\end{array}$ & Onyx & Short & MarkTwo & Impact & ISO 179 \\
\hline Yu et al. [27] & $\begin{array}{l}\text { Process parameter influence } \\
\text { on mechanical properties, } \\
\text { predictive model }\end{array}$ & $\begin{array}{l}\text { Infill pattern, fiber } \\
\text { volume fraction }\end{array}$ & Onyx/CF & Continuous & MarkOne & Tensile, flexural & $\begin{array}{l}\text { Custom dogbone design } \\
\text { ASTM D6272-17 }\end{array}$ \\
\hline
\end{tabular}




\subsubsection{Continuous Fiber Fabrication-Markforged Printers}

To turn a digital model into a physical part in 3DP process, the CAD model is prepared using slicing software. The open access Eiger slicing software is used in commercially available Markedforged printers. Changes in print parameters such as nozzle temperature, nozzle speed, thickness of deposited layer are restricted. However, process parameters such as infill density, infill pattern, fiber pattern and orientation can be altered to tailor the mechanical properties. Markforged printers allow two different fiber patterns, namely unidirectional (referred to as isotropic in the software and some literature) and concentric. Combinations of the two patterns can also be obtained within the same layer. Fibers can be printed at any given angle with 0.01 of a degree resolution. On the other hand, the concentric configuration takes the outer geometry and offsets it inward to create the fiber pattern. It is possible to control the number of fiber rings in each layer. Figure 8 shows schematic view of three different fiber patterns. Fibers are continuous in each layer but the fibers do not bridge layers. When fabricating a fiber layer, the bare end of the fiber is first laid down and ironed in with the flat tip of the print head. This ironing action of the print head change the fiber filament from circular to an elliptical geometry after being deposited on the bed. Once the pattern is finished, a blade cuts the fiber and proceeds to the next layer. This start point of the fiber layer is moved for each layer so no specific corner would be the weak point in the structure. This start point can be seen in Figure 8. The user has two choices of matrix, and three choices for fiber reinforcement. The matrix can be either nylon, or onyx which is chopped carbon fiber reinforced nylon and the fiber can be carbon, glass, or Kevlar. Fiber volume fraction for each specimen can be altered by changing the number of fiber layers. The Eiger software returns the fiber and matrix volumes, however, the software calculation does not account for the volume of binding agent present in each fiber filament nor the chopped CF in the matrix phase (onyx).

(a)

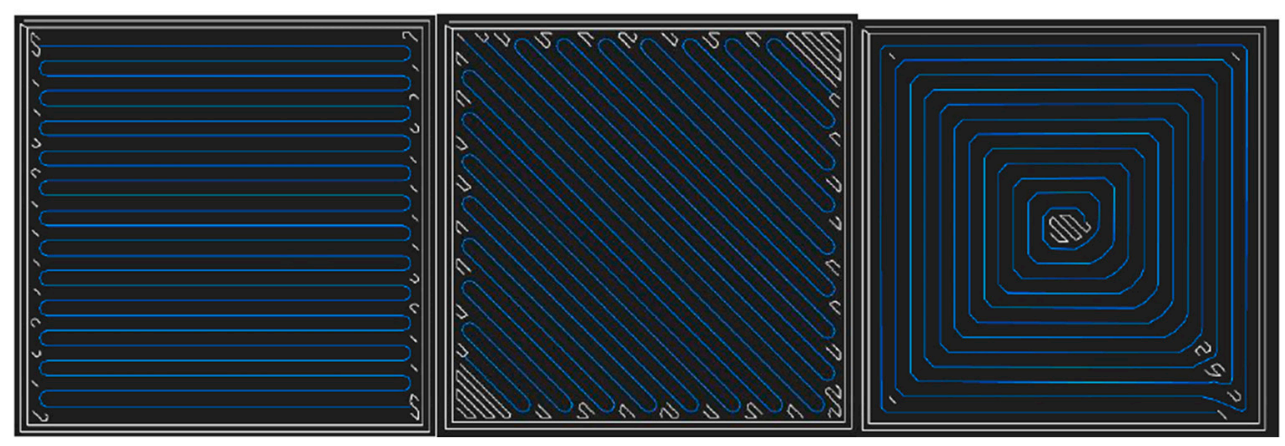

Figure 8. Fiber configurations: (a) unidirectional fiber pattern at $0^{\circ}$ (horizontal load direction); (b) unidirectional fiber pattern at $45^{\circ}$; (c) concentric fiber pattern.

\subsubsection{In-Nozzle Impregnation}

While this method is not commercially available, in-nozzle impregnation promises mechanically enhanced properties due to impregnation of fibers into matrix before deposition. Matsuzaki et al. [14] developed an in-house in-nozzle impregnation process such that the fiber and matrix filament are separately fed into the nozzle and heated by the nozzle head, the fiber is heated before entering the nozzle and the matrix is melted by the heater inside the printer head, therefore consolidating the fiber and matrix. The impregnated fibers are laid out on an $80^{\circ} \mathrm{C}$ heated bed. The new print approach was developed based on modifying the print head of the commercially available FDM 3D printer Blade-1 printer with existing preheating mechanism. The diameter of the resin filament is $0.45 \mathrm{~mm}$ larger than the diameter of the nozzle to ensure adequate pressure for the impregnation of resin into the fiber bundles in the nozzle. Their studied fiber volume fraction was slightly higher than $6 \%$. The in-nozzle impregnation has the promise of better fiber-matrix interface, but no study has been conducted on interfacial properties of in-nozzle impregnation process. 
Both process types have their limitations related to the currently available hardware solutions. Moreover, the choice of matrix and fiber materials used in 3DP fiber composites is limited. Short fiber reinforced polymer filaments can be used on general-purpose 3D printers and thus some of the limitations encountered on dedicated 3D printers are reduced. However, efficiently controlling the process and tailoring outcomes behavior is still a challenge.

\subsection{D Printing Process Parameters for Fiber Reinforced Composites}

Studies have shown that using the same material and printer, depending on the choice of process parameters, the mechanical properties can be vastly different. There is no universal set of parameters that works for all applications; Therefore, such parameters should be optimized depending on the mechanical properties of interest, matrix and fiber materials, type of printer, etc. Table 1 summarizes the studied process parameters for fiber reinforced composites in the literature.

\subsubsection{Infill Pattern and Density}

To expedite the printing process, printers are programed to build a part by moving at a predetermined pattern. The infill pattern can be triangular, rectangular and hexagonal and the infill density can change from $20 \%$ to $100 \%$ (solid infill). Several studies have been dedicated to determine the relation between the infill pattern, density and the mechanical properties of the 3DP specimens. Gonzalez-Estrada et al. [21] studied the influence of different infill pattern of Nylon matrix (triangular, rectangular and hexagonal) at two infill densities $(20 \%$ and $50 \%)$ on the tensile strength. The testing results showed that the triangular pattern performed the best and also that the increase of the infill density from $20 \%$ to $50 \%$ produces only a 3.3\% increase in the Young's modulus and $5.5 \%$ in the tensile strength. Yasa et al. [30] research also focused on infill density's effect on the tensile properties, noticing that an increase from $50 \%$ to $75 \%$ of infill density resulted in an increase of 5-6\% of the Young's Modulus and yield strength, but a decrease from $25 \%$ to $20 \%$ in ductility. The comparison was made by using specimens from Onyx built with a triangular filling pattern. The same type of specimens (Onyx, 50\%, 75\%, 100\% infill density and triangular pattern) was used also for analyzing the impact toughness [31]. Tests results indicated a reduction of the toughness when changing the infill density from $100 \%$ to $75 \%$ from 49.53 to $25.28 \mathrm{~kJ} / \mathrm{m}^{2}$, and further to $22.7 \mathrm{~kJ} / \mathrm{m}^{2}$ for the $50 \%$ dense specimens.

De Toro et al. [32] investigated the tensile and compressive properties of CF-reinforced composites (commercial filament made of PA6 and $20 \mathrm{wt} \%$ short CF) for specimens manufactured with $60 \%$ infill density and three different matrix infill patterns (unidirectional $0^{\circ}$, linear $\pm 45^{\circ}$, triangular). The tensile strength, Young's modulus and yield strength were better for the unidirectional pattern, while the triangular pattern performed better than the linear pattern at $\pm 45^{\circ}$. The compressive properties were also better for the unidirectional pattern specimens. When comparing $100 \%$ density unidirectional samples with injected samples, it was found that the injected samples performed $4 \%$ better in terms of yield strength, while the Young's modulus was improved by 50\% in the case of the unidirectional $100 \%$ dense 3D-printed samples. Infill densities of $70 \%, 80 \%, 90 \%$ and $100 \%$ were investigated in correlation to compressive properties by Abdullah et al. [33], their results showing similar performance for the infill density values higher than $70 \%$.

The research of Naranjo-Lozada et al. [8] focused on onyx specimens with $10 \%$ and $70 \%$ infill density and rectangular and triangular infill pattern for analyzing their impact on the tensile behavior. According to their results, the Young's modulus provided by the $10 \%$ triangular pattern is higher than that of the $70 \%$ rectangular pattern, while the reported tensile strength at yield was almost similar for both infill densities. This confirms the results of Gonzalez-Estrada et al. [21], the explanation being that the triangular pattern has more strands oriented in the direction of loading $\left(0^{\circ}\right)$ than the rectangular pattern. Another interesting conclusion was that the infill density is not largely influencing the tensile properties (also considering the small dimensions of specimens), while significantly affecting the printing time and cost. 


\subsubsection{Fiber Orientation, Volume Fraction and Stacking Sequence}

Mechanical properties of composite specimens highly depend on the orientation of fibers. Fibers are the load carrying constituent in the longitudinal direction and source of stress concentration in the transverse direction. Intrinsic anisotropy of composites requires determination of properties at different directions. To determine the Young's modulus and strength, specimens with fibers oriented at $0^{\circ}$, $90^{\circ}$, and $\pm 45^{\circ}$ are manufactured and tested to find longitudinal, transverse and shear properties, respectively. In functional applications, 3D-printed parts experience complex stress state, therefore, unidirectional composites are rarely used and a laminate with an optimized stacking sequence for a given property is preferred. In 3DP of composite laminates, any stacking sequence can be easily achieved. However, there are a couple of distinctions that need to be considered when reading 3D-printed specimen lay-ups. The composite is in a shell of matrix with two or more layers of floor (bottom layers), roof (top layers) and wall/shell (surrounding layers). In Markforged 3D printers, each layer can be either fiber or matrix, and the combination of the two is not possible. Therefore, the researchers have either consolidated all the fiber layers together or alternated between fiber and matrix layers. All 3D-printed specimens described in surveyed literature have at least one floor layer and top layer of matrix with the exception of Todoroki et al. research [23] in which specimens with no surface layers were studied. Stacking sequence could be the combination of concentric as well as unidirectional fibers providing much more variety of analysis.

Araya-Calvo et al. [4] studied compressive strength for specimens with 24 reinforced layers, two wall layers, four floor and four roof layers. Nylon layers were printed at $100 \%$ infill density with rectangular pattern. The reinforced layers were distributed in the sample in three different configurations: (a) 12 layers at each end of the specimen, (b) 8 layers at each end and 8 layers at the center, (c) 24 layers placed in alternate equidistant layers. For each configuration, two separate patterns, (a) concentric and (b) unidirectional pattern, were tested. The experimental results showed that the configuration with alternating layers and concentric fiber pattern returned the highest compressive modulus (1.690 GPa) and compressive proportional limit (40.5 MPa). It must be noted that their study did not investigate consolidating all fiber layers in the center. Three different fiber volume fractions were tested at the selected configuration (alternating with circular fiber patterns), the result showing that the highest tested fiber volume fraction $(24.44 \%)$ returns the highest modulus and proportional limit. Pyl et al. [29] studied flexural and in-shear properties for six different configurations: (a) $4 \mathrm{~N}-18 \mathrm{C}-4 \mathrm{~N}$; (b) $2 \mathrm{~N}-8 \mathrm{C}-2 \mathrm{~N}$; (c) $1 \mathrm{~N}-8 \mathrm{C}-2 \mathrm{~N}$; (d) $1 \mathrm{~N}-8 \mathrm{C}-1 \mathrm{~N}$; (e) $1 \mathrm{~N}-8 \mathrm{C} / \mathrm{N}-1 \mathrm{~N}$; (f) $2 \mathrm{~N}-5 \mathrm{C} / \pm 45^{\circ} \mathrm{N}-2 \mathrm{~N}$, where $N$ represent Nylon and $\mathrm{C}$ carbon fiber layers. The results indicated that by alternating layers of matrix and reinforcement, the composite's stiffness reduces. Van der Klift et al. [28] evaluated the tensile strength of unidirectional specimens with 10 layers in two configurations: (a) $2 \mathrm{~N}-6 \mathrm{CF}-2 \mathrm{~N}$; (b) $4 \mathrm{~N}-2 \mathrm{CF}-4 \mathrm{~N}$. CF layers were deposited in a unidirectional pattern and the Nylon layers were 3D-printed at $100 \%$ infill with no information on their infill pattern. The strain to failure of the $2 \mathrm{CF}$ specimens was approximately one third of that of the $6 \mathrm{CF}$ specimens which one would expect as the fiber volume fraction is much lower.

Similar to conventional composites, the mechanical properties of a 3D-printed composite part are driven by the fiber volume fraction. Increasing the fiber volume fraction improves the impact properties [6], as well as strength and stiffness [7]. Araya-Calvo et al. [4] studied the optimized fiber volume fraction for the compressive strength and the flexural stress as $24.44 \%$ and $48.93 \%$, respectively. Therefore, one should be cognizant of the effect of fiber volume fraction when comparing mechanical tests results. To determine the properties at a given fiber content, predictive rules of mixture must be used for variety of fiber volume fractions, discussed in the next section.

One unique feature of composite 3DP is the capability of placing concentric rings as reinforcement. The effect of number of rings on the specimens' fatigue was studied by Imeri et al. [22]. Specimens with combinations of unidirectional as well as concentric patterns were printed using MarkTwo $3 \mathrm{D}$ printer. The results revealed that increasing the number of concentric rings improves fatigue life, as the fiber volume fraction increases. However, adding concentric fiber rings to unidirectional 
specimens decreases the fatigue life, and purely unidirectional sample with no concentric fiber ring endures the highest number of cycles to failure under tension-tension fatigue loading. Unidirectional specimens $\left(0^{\circ}\right)$ performed better in terms of tensile strength followed by $0^{\circ} / 90^{\circ} \mathrm{CF}$ orientation $[25,29]$. In terms of fatigue resistance, specimens with zero rings and unidirectional pattern performed the best [22,34]. Naranjo-Lozada et al. [8] observed that the tensile behavior of samples with one, three and five concentric rings and unidirectional pattern were compared. Results showed that the specimens with five concentric rings have the largest elastic modulus as also having the largest CF volume fraction. At the same CF volume fraction, the number of rings (one or three) is not significantly influencing the elastic moduli. Yu et al. [27] compared the flexural strength of 3D-printed specimens with concentric and unidirectional patterns observing better flexural performance for the concentric pattern. A fiber volume fraction of $48.72 \%$ provided the best flexural strength. In terms of tensile strength, the specimens with eight $\mathrm{CF}$ layers and three rings performed the best, these having also the largest CF content. Sanei et al. [9] mitigated the effect of stress concentration by printing two fiber rings around an open hole tensile specimen. They observed that the failure initiated at the stress concentration region, but were blocked by the fiber and traveled around the hole. In general, specimens with unidirectional fiber pattern perform better in uniaxial stress state, and the addition of fiber rings only helps when results in higher fiber volume fraction and is mainly used for strengthening a region of interest.

\subsubsection{Build Orientation}

3DP has the advantage of printing specimen in a flat, upright or side position. Studies have shown that the print orientation can influence the resulted mechanical properties significantly. The additive sequence of depositing layers creates anisotropy in the specimen, therefore, causing the build orientation to be an important factor. As requirement for the specimen geometry is different for various mechanical testing, the upright position reaches the print size limitation of printers for tensile and compressive specimen, and therefore, studies have focused on side and flat positions. Figure 9 shows different built orientations for tensile (Figure 9A) and impact specimens (Figure 9B). For the non-reinforced 3D-printed polymers [19] this parameter was extensively studied, and relations were presented, while, only few studies have focused on build orientation for the CF-reinforced 3D-printed composites. However, build orientation is even more significant with the presence of fibers due to orientation of fibers and the interface between fiber filaments with respect to load direction. As the fiber bundle is no longer circular after printing and it takes an elliptical shape with greater width than thickness, the build orientation also affects the maximum fiber volume fraction that a specimen can have.

Caminero et al. [6] studied the influence of the build orientation and reinforcement scheme over the impact resistance. Three reinforcement materials(CF, KF, GF) and two build directions were investigated for Charpy specimens built on MarkTwo 3D printer with unidirectional pattern. Layers of fibers were placed along the specimen longest direction. They studied two built orientation referred to as flat (notch on the side) and on edge (notch side up) specimen. The two types of specimens had similar CF volume fraction. Their results showed that for unreinforced specimen, the notch on side configuration shows higher impact energy absorption while for reinforced specimen, the notch side up configuration showed highest impact energy absorption. They also found that the impact resistance is directly correlated to fiber volume fraction. A continuation of this research is presented in [7] (using the same specimens' layer designs and reinforcement) indicating that flat built specimens have higher strength and stiffness than the on-edge specimens.

Carbon fiber reinforced ABS composites were investigated by Wang et al. [37] for two build orientations and two raster orientations. Results showed that side specimens' flexural properties were superior to the flat specimens. Yasa et al. [30] study indicated that elongation at break was smaller for side Onyx specimens, while Young's modulus and yield strength were higher. 


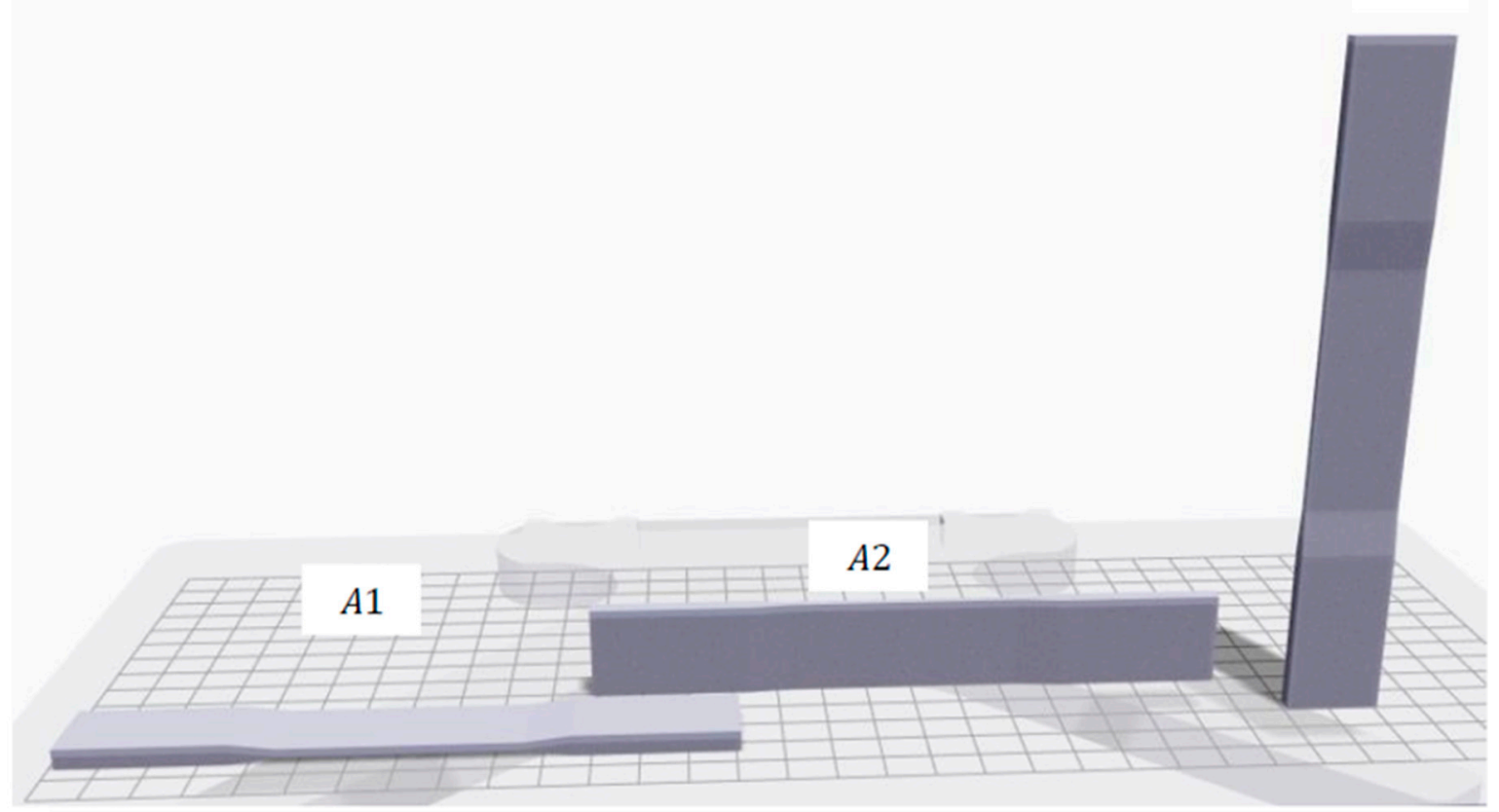

(A)

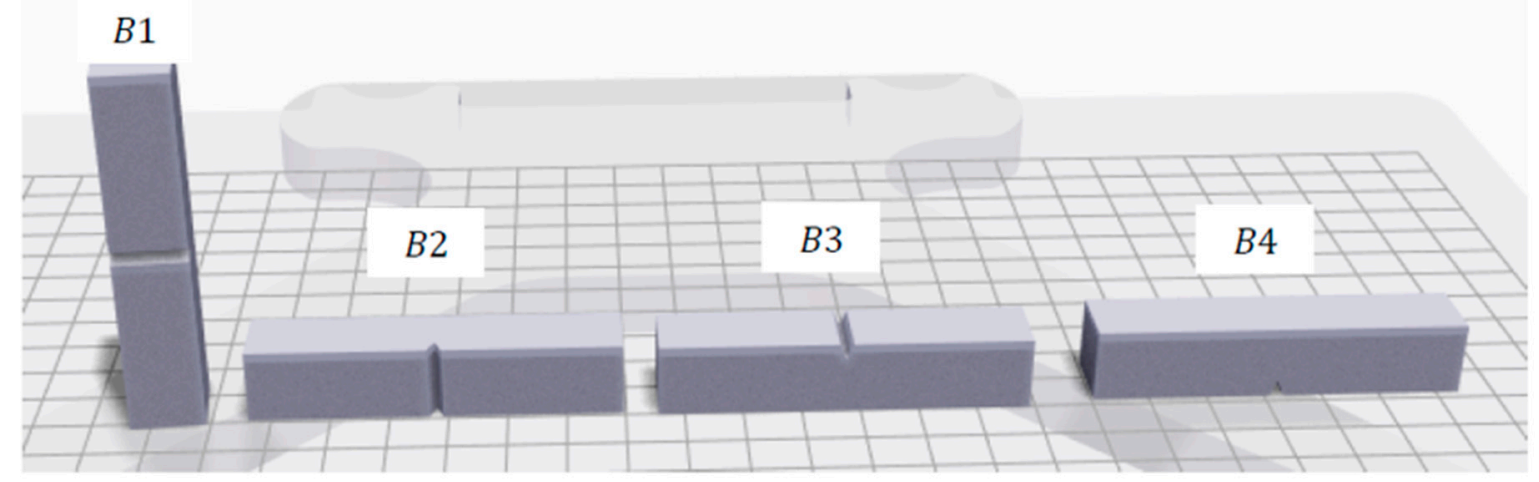

(B)

Figure 9. Build orientation for (A) tensile coupons: (A1) flat, (A2) sideways (A3) vertical. (B) Impact Charpy samples: (B1) vertical, (B2) horizontal with notch on the side, (B3) horizontal with notch up, (B3) horizontal with notch down.

Ding et al. [39] also analyzed the upright build orientation for PLA/chopped carbon fiber specimens. In two build directions, the load is parallel to the cross section, while for the flat specimen the load is perpendicular to the fibers direction. Tensile and impact behavior is better for the specimens in flat build orientation, followed by the specimens in upright build orientation.

\subsubsection{Specimens Design and Tabs}

In the absence of standards dedicated to the evaluation of the mechanical behavior of 3D-printed fiber reinforced composites, there is no consensus on the specimen design. Not all studies are designed around the same type of specimen for assessing a certain mechanical property, in some cases custom design was used (refer to Table 2). However, the majority of the reviewed studies were based on the American Society for Testing and Materials (ASTM) standards for plastic and composite materials.

The tensile properties were commonly evaluated using ASTM 3039 and ASTM D638 type I, type IV and type V or modified type IV proposed by Croccolo et al. [52] (their design includes a larger radius, $244 \mathrm{~mm}$ instead of $76 \mathrm{~mm}$, to reduce the stress concentrations and avoid the initiation of crack). 
Frank et al. [28] used the JIS K7073 standard, mentioning that 3D-printed specimens often fail near the tabs-an observation also confirmed by other researchers using other specimens' designs [48].

To the best of our knowledge, 3DP literature provides only few studies relating the specimens' design to the mechanical properties testing results. Two of these studies $[53,54]$ discussed the 3D-printed specimens from polymers, while Pyl et al. [29] addressed this subject for the continuous CF reinforced composites, their experimental investigations showing that the shape of the dogbone is not affecting the tensile strength results (comparison between ASTM D638 type I, type IV and modified type IV), but the rectangular specimens outperformed the dogbone specimens [29].

As composite longitudinal tensile strength are much higher than transverse compressive strength, tensile coupons need to be tabbed at the grip regions to prevent compressive failure. To allow for gradual transition of cross sections, taps are tapered anywhere between $5^{\circ}$ to $85^{\circ}$. Sanei et al. [9] printed the tab along with the specimen. They reinforced the tab with CF as well.

Pyl et al. [29] analyzed the effect of tabs by testing three different types of tabs: (1) 3D-printed tabs with reinforcements, (2) 3D-printed tabs from Nylon with no reinforcements and (3) paper tabs. Their results showed no significant difference in the tensile strength. Tapered and non-tapered specimens were also tested, showing that the tabs' shape is not influencing the measured tensile property [28].

\subsubsection{Start/End Point of Fibers}

It has been shown that the mechanical behavior of composite specimens depend on the start/end points of the fiber [28]. Therefore, in preparation of specimens, efforts have been made to avoid including these locations within the specimens gage length. To that end, the testing specimens were cut and extracted from larger oval or rectangular 3D-printed parts $[5,8,23,24,46,48]$ to ensure the fiber beginnings and ends fall outside the tabbing area in tensile testing and beyond the support in flexural testing. Cutting the specimen from a larger part has an additional advantage of ensuring truly unidirectional pattern, otherwise, for unidirectional fiber pattern, the tool path makes a U-turn when reaches the boundary of specimen before starting to deposit another fiber bundle. Such fiber curvature on the edges will create multiaxial stress state.

\subsection{Defects in 3D-Printed Composite Specimens}

The major reported defect in 3DP continuous fiber composite is the formation of voids, also referred to as air pockets or porosity. Presence of voids is not unique to 3DP and is a known defect in conventional composites [54-56]. However, the voids formation is significant in 3DP due to the additive deposition of filaments and layers. There are abundance of studies reporting voids at different length scales using different materials, 3D printers and process parameters. Voids can appear at multiple length scales in 3D-printed parts: (a) micro voids within fiber and matrix filament, (b) meso voids between fiber bundles after deposited within a layer and (c) macro voids between layers. The effect of nozzle geometry in voids formation was studied in [5]. Ning et al. showed the presence of voids in form of gas bubbles, interbead voids and fiber pull out [12]. Post-processing of 3D-printed samples by application of pressure and heat can reduce the void content at a cost of geometrical accuracy, time and cost. The second major defect is the waviness of fibers in nominally unidirectional specimens. Due to lack of pretension in the 3DP-process, fibers have large degree of waviness (see Figure 10A). Such waviness degrades the mechanical properties. The other major defect is the poor bonding between fiber and the matrix phase. While individual fiber filaments are bonded in the fiber bundle using a binding agent, the fiber and matrix are not mixed at the nozzle and placed at different layers. Such lack of binding and impregnation degrades the mechanical properties. Ivey et al. [40] observed that increasing annealing temperature helps consolidation of fiber and matrix resulting an improvement in modulus and strength of both neat and reinforced PLA. Figure 10 shows a micrograph of 3D-printed composite microstructure, highlighting voids formation and fiber waviness. 

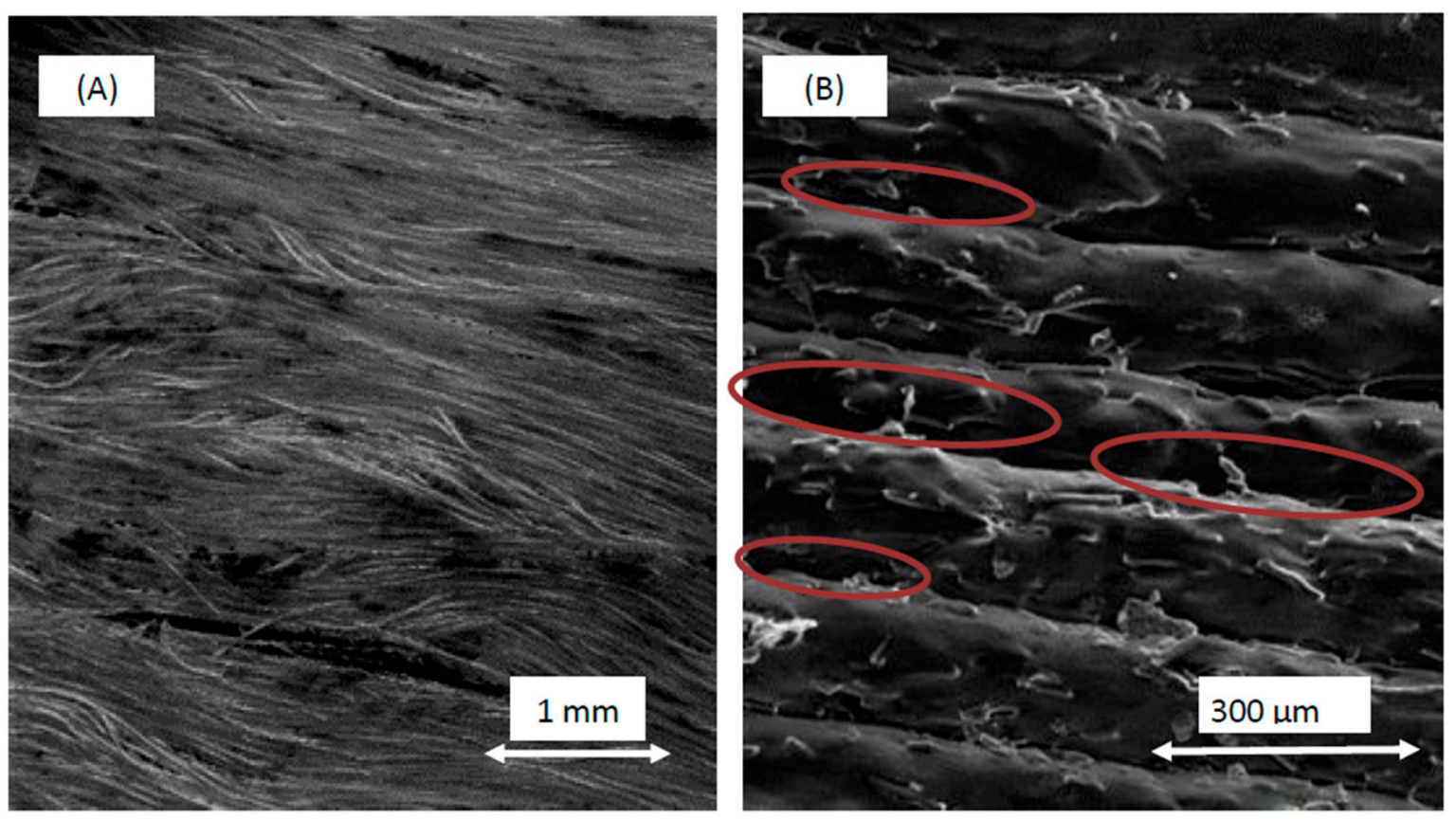

Figure 10. Scanning electron microscope image of 3D printed CF/onyx composite microstructure using MarkTwo (A) showing waviness in nominally unidirectional composites, (B) showing voids between deposited filaments (image acquired by the authors).

\subsection{Specimen Size Effect}

Mechanical properties of specimens depend on their overall geometrical size. Larger specimens tend to have more defects altering the mechanical behavior. For instance, for a larger specimen the printer needs to travel a longer distance before another layer is deposited on the specimen, hence changing the cooling pattern. For conventional composites, larger samples result in poorer mechanical properties [57]. However, there has not been much research dedicated to specimen size effect of 3D-printed fiber reinforced composites. Goh et al. [45] used a MarkOne 3D printer to build specimens of 23 layers with unidirectional fiber pattern (ASTM D3039, $250 \times 25 \times 2.5 \mathrm{~mm}$ ) with $0.1 \mathrm{~mm}$ layer thickness and $41 \%$ volume of $\mathrm{CF}$, the resulted tensile strength reported as $600 \pm 30 \mathrm{MPa}$. Justo et al. [48] also used MarkOne 3D printer and a filament material with approximately $40 \%$ fiber weight, but their specimens' dimensions were $250 \times 12.5 \times 1 \mathrm{~mm}$. The reported value for $0^{\circ}$ tensile strength was $701.41 \pm 70 \mathrm{MPa}$.

The size of the specimen could limit the choice of design parameters. For instance, the dimension of standard specimens in gage area is limiting the number of printed concentric fiber rings to maximum six for the dogbone specimen [24], while for the rectangular specimens $(250 \times 25 \times 2.5 \mathrm{~mm})$, the influence of up to 12 concentric rings was investigated [15]. Moreover, the standard specimen thickness restricts the number of possible stacking sequence.

\subsection{Micromechanical Models}

Micromechanical models are used to predict the mechanical properties of composite based on constituents' properties and the morphology of microstructure [58,59]. While various models have been extensively studied and validated for conventional composites, their validity for 3D-printed parts has been sparsely studied. Studies that have evaluated the effectiveness of such models for various mechanical properties are summarized further. 


\subsubsection{Voigt Model}

The Voigt model, which assumes equal longitudinal strain in the matrix and fiber in the longitudinal direction, is used to predict longitudinal properties and expressed as:

$$
X_{1}=v_{f} \cdot X_{f}+\left(1-v_{f}\right) \cdot X_{m}
$$

where $X_{1}, X_{f}$ and $X_{m}$ are composite, fiber and matrix property of interest, respectively, in the longitudinal direction and $v_{\mathrm{f}}$ denotes the fiber volume fraction. The Voigt model is commonly used for prediction of longitudinal properties. Bakis used this model for Poisson's ratio [35], Al Abadi et al. used this for longitudinal modulus [15].

\subsubsection{Reuss Model}

The inverse rule of mixture, or Reuss model predicts a lower bound on the transverse properties based on the assumption of equal stresses of constituents in the transverse direction and expressed as;

$$
X_{2}=\left(\frac{v_{f}}{X_{f}}+\frac{1-v_{f}}{X_{m}}\right)^{-1}
$$

\subsubsection{Halpin-Tsai Model}

The Halpin-Tsai model is a semi-empirical model providing a more accurate prediction of transverse properties in comparison to the Ruess model,

$$
X_{2}=X_{m}\left(\frac{1+\zeta \cdot \eta \cdot v_{f}}{1-\eta \cdot v_{f}}\right)
$$

where $\eta$ is given by:

$$
\eta=\frac{\left(\frac{X_{f}}{X_{m}}\right)-1}{\left(\frac{X_{f}}{X_{m}}\right)+\zeta}
$$

and $\zeta$ is an experimental fitting parameter ranging from 1 to 2 for continuous fiber and $2 l / D$ for short chopped fiber, where $l$ is the length and $D$ is the diameter of short fiber. Halpin-Tsai has been used for transverse and shear properties of 3D printed part with reasonable accuracy $[9,35,40]$.

\subsubsection{Volume Average Stiffness (VAS) Method}

Kregers et al. developed the VAS method for conventional composites [60-62]. Melenka et al. [14] applied the VAS method to 3D-printed composites. They used micromechanics method to determine the effective properties for solid, infill and shell layers in their corresponding local coordinates, then coordinate transformation was performed to transfer each stiffness matrix to the global coordinate system. Volume averaging was performed to form the overall stiffness matrix. VAS works well for longitudinal modulus and poorly for transverse modulus. The VAS method proved to be effective for Young's modulus of Glass and Kevlar [15].

\subsubsection{Generalized Self-Consistent Method}

Christensen presented this method for evaluating the transverse properties for a transversely isotropic medium containing void in an isotropic matrix phase [63]. Bakis et al. results showed that this method overpredicted the longitudinal and transverse moduli [35].

Micromechanical models are as accurate as their underlying assumptions. Idealized models fail to include key microstructural features such as interphase properties, void content and fiber waviness. As there is a large uncertainty in such features, deterministic models have limited use for functional parts and stochastic models based on the observed variability need to be developed for better prediction 
of whole spectrum of mechanical properties, however, no stochastic approach has been attempted for 3D-printed composite specimens to date.

\section{Concluding Remarks and Future Suggestions}

Combining the high specific strength/stiffness of composite materials with unique capabilities of 3DPin manufacturing complex geometries has promising applications in biomedical, aerospace, and automotive sectors. After reviewing the literature in evaluating the mechanical properties of 3D-printed CF reinforced composites, several concluding remarks and suggestions for future area of research are presented here:

(1) 3DP of composite materials offers a great potential for manufacturing functional parts beyond prototyping due to exceptional specific stiffness and strength that composites are known for with the addition of unique features of $3 \mathrm{DP}$ such as printing concentric fibers around notches to mitigate stress concentration, changing the print process parameter to tailor the mechanical properties.

(2) The lack of reporting details makes the comparison between different research efforts challenging. In many instances, information about the infill pattern, infill density, fiber volume fraction, number of floor/roof were left out, each of which could result in noticeable difference in the resulted mechanical properties. Authors would like to take a note to authors/reviewers to ensure the inclusion of such details for the reproducibility of their findings.

(3) A limited research has been conducted on the quantification of defects and their contribution to the overall mechanical properties, voids formation at different length scale has been the major reported defect in the literature.

(4) Large uncertainty present in the specimen microstructures renders the deterministic analysis invalid, and a stochastic predictive model must be developed. Authors did not find any stochastic analysis linking microstructural uncertainty to mechanical property variability for 3D-printed continuous fiber composites.

(5) Despite many patents on the topic [64], to this date, Markforged printers are the only commercially available 3D printers for manufacturing continuous fiber composites. Poor adhesion between fiber and matrix layer, lack of tension in fibers, presence of void, limited choice of matrix material (nylon and onyx) are the reported restricted factors.

(6) It has been reported that for a given fiber volume fraction, consolidating fiber layers compared to alternating fiber/matrix layers will enhance the mechanical properties.

(7) The use of concentric fiber rings is the unique capability of 3DP that has been used to optimize the mechanical properties and mitigate stress concentration.

(8) Triangular pattern shows higher mechanical properties compared to rectangular or hexagonal patterns. It was also observed that infill density is not largely influencing the tensile yield strength nor the ultimate strength while reducing elongation and significantly affecting the printing time and cost.

(9) Tensile strength is the most studied mechanical property for both short and continuous reinforced 3D-printed composites followed by flexural, compressive and shear.

(10) All studies are focused on experimental coupons with no reports on parts in service when exposed to sterilization, light, aging or humidity.

(11) Given the large number of processing parameter needed be selected in printing composite samples, an artificial intelligence (AI) approach in optimizing said parameters to get desirable outcome would be the next milestone in 3D printing of composite materials.

(12) Specific design rules need to be developed for 3D-printed fiber reinforced composite parts as significant rise in the number of studies in the field is expected in the next couple of years, triggered by the industry interest and sustained by the researchers and equipment developers' work.

Funding: This research received no external funding. 
Conflicts of Interest: The authors declare no conflict of interest.

\section{References}

1. Kabir, S.M.F.; Mathur, K.; Seyam, A.F.M. A critical review on 3D printed continuous fiber-reinforced composites: History, mechanism, materials and properties. Compos. Struct. 2020, 232, 111476. [CrossRef]

2. Brenken, B.; Barocio, E.; Favaloro, A.; Kunc, V.; Pipes, R.B. Fused filament fabrication of fiber-reinforced polymers: A review. Addit. Manuf. 2018, 21, 1-16. [CrossRef]

3. Zak, G.; Sela, M.N.; Park, C.B.; Benhabib, B. A layered manufacturing of fiber reinforced composites. J. Manuf. Sci. Eng. 1999, 121, 448-456. [CrossRef]

4. Araya-Calvo, M.; López-Gómez, I.; Chamberlain-Simon, N.; León-Salazar, J.L.; Guillén-Girón, T.; Corrales-Cordero, J.S.; Sánchez-Brenes, O. Evaluation of compressive and flexural properties of continuous fiber fabrication additive manufacturing technology. Addit. Manuf. 2018, 22, 157-164. [CrossRef]

5. Blok, L.G.; Longana, M.L.; Yu, H.; Woods, B.K.S.S. An investigation into 3D printing of fibre reinforced thermoplastic composites. Addit. Manuf. 2018, 22, 176-186. [CrossRef]

6. Caminero, M.A.; Chacón, J.M.; García-Moreno, I.; Rodríguez, G.P. Impact damage resistance of 3D printed continuous fibre reinforced thermoplastic composites using fused deposition modelling. Compos. Part B Eng. 2018, 148, 93-103. [CrossRef]

7. Chacón, J.M.; Caminero, M.A.; Núñez, P.J.; García-Plaza, E.; García-Moreno, I.; Reverte, J.M. Additive manufacturing of continuous fibre reinforced thermoplastic composites using fused deposition modelling: Effect of process parameters on mechanical properties. Compos. Sci. Technol. 2019, 181, 107688. [CrossRef]

8. Naranjo-Lozada, J.; Ahuett-Garza, H.; Orta-Castañón, P.; Verbeeten, W.M.H.; Sáiz-González, D. Tensile properties and failure behavior of chopped and continuous carbon fiber composites produced by additive manufacturing. Addit. Manuf. 2019, 26, 227-241. [CrossRef]

9. Sanei, S.H.R.; Arndt, A.; Doles, R. Open hole tensile testing of 3D printed continuous carbon fiber reinforced composites. J. Compos. Mater. 2020. [CrossRef]

10. Mohammadizadeh, M.; Imeri, A.; Fidan, I.; Elkelany, M. 3D printed fiber reinforced polymer composites-Structural analysis. Compos. Part B Eng. 2019, 175, 107112. [CrossRef]

11. Oztan, C.; Karkkainen, R.; Fittipaldi, M.; Nygren, G.; Roberson, L.; Lane, M.; Celik, E. Microstructure and mechanical properties of three dimensional-printed continuous fiber composites. J. Compos. Mater. 2019, 53, 271-280. [CrossRef]

12. Ning, F.; Cong, W.; Qiu, J.; Wei, J.; Wang, S. Additive manufacturing of carbon fiber reinforced thermoplastic composites using fused deposition modeling. Compos. Part B Eng. 2015, 80, 369-378. [CrossRef]

13. Melenka, G.W.; Cheung, B.K.O.O.; Schofield, J.S.; Dawson, M.R.; Carey, J.P. Evaluation and prediction of the tensile properties of continuous fiber-reinforced 3D printed structures. Compos. Struct. 2016, 153, 866-875. [CrossRef]

14. Matsuzaki, R.; Ueda, M.; Namiki, M.; Jeong, T.K.; Asahara, H.; Horiguchi, K.; Nakamura, T.; Todoroki, A.; Hirano, Y. Three-dimensional printing of continuous-fiber composites by in-nozzle impregnation. Sci. Rep. 2016, 6, 1-7. [CrossRef] [PubMed]

15. Al Abadi, H.; Thai, H.T.; Paton-Cole, V.; Patel, V.I. Elastic properties of 3D printed fibre-reinforced structures. Compos. Struct. 2018, 193, 8-18. [CrossRef]

16. Ferreira, R.T.L.; Amatte, I.C.; Dutra, T.A.; Bürger, D. Experimental characterization and micrography of 3D printed PLA and PLA reinforced with short carbon fibers. Compos. Part B Eng. 2017, 124, 88-100. [CrossRef]

17. Somireddy, M.; Singh, C.V.; Czekanski, A. Mechanical behaviour of 3D printed composite parts with short carbon fiber reinforcements. Eng. Fail. Anal. 2020, 107, 1-13. [CrossRef]

18. van de Werken, N.; Tekinalp, H.; Khanbolouki, P.; Ozcan, S.; Williams, A.; Tehrani, M. Additively manufactured carbon fiber-reinforced composites: State of the art and perspective. Addit. Manuf. 2020, 31, 100962. [CrossRef]

19. Popescu, D.; Zapciu, A.; Amza, C.; Baciu, F.; Marinescu, R. FDM process parameters influence over the mechanical properties of polymer specimens: A review. Polym. Test. 2018, 69, 157-166. [CrossRef] 
20. Liberati, A.; Altman, D.G.; Tetzlaff, J.; Mulrow, C.; Gøtzsche, P.C.; Ioannidis, J.P.A.; Clarke, M.; Devereaux, P.J.; Kleijnen, J.; Moher, D. The PRISMA Statement for Reporting Systematic Reviews and Meta-Analyses of Studies That Evaluate Health Care Interventions: Explanation and Elaboration. PLoS Med. 2009, 6, e1000100. [CrossRef]

21. González-Estrada, O.A.; Pertuz, A.; Quiroga, J. Evaluation of tensile properties and damage of continuous fibre reinforced 3D-printed parts. Key Eng. Mater. 2018, 774, 161-166. [CrossRef]

22. Imeri, A.; Fidan, I.; Allen, M.; Wilson, D.A.; Canfield, S. Fatigue analysis of the fiber reinforced additively manufactured objects. Int. J. Adv. Manuf. Technol. 2018, 98, 2717-2724. [CrossRef]

23. Todoroki, A.; Oasada, T.; Mizutani, Y.; Suzuki, Y.; Ueda, M.; Matsuzaki, R.; Hirano, Y. Tensile property evaluations of 3D printed continuous carbon fiber reinforced thermoplastic composites. Adv. Compos. Mater. 2020, 29, 147-162. [CrossRef]

24. Dickson, A.N.; Barry, J.N.; McDonnell, K.A.; Dowling, D.P. Fabrication of continuous carbon, glass and Kevlar fibre reinforced polymer composites using additive manufacturing. Addit. Manuf. 2017, 16, 146-152. [CrossRef]

25. Dutra, T.A.; Ferreira, R.T.L.; Resende, H.B.; Guimarães, A. Mechanical characterization and asymptotic homogenization of 3D-printed continuous carbon fiber-reinforced thermoplastic. J. Braz. Soc. Mech. Sci. Eng. 2019, 41. [CrossRef]

26. Sarvestani, A.N.; Werken, N.; van de Khanbolouki, P.; Tehrani, M. 3D Printed Composites with Continuous Carbon Fiber Reinforcements. In Proceedings of the ASME 2017 International Mechanical Engineering Congress and Exposition, Tampa, FL, USA, 3-9 November 2017; pp. 1-6.

27. Yu, T.; Zhang, Z.; Song, S.; Bai, Y.; Wu, D. Tensile and flexural behaviors of additively manufactured continuous carbon fiber-reinforced polymer composites. Compos. Struct. 2019, 225. [CrossRef]

28. Frank, V.D.K.; Koga, Y.; Todoroki, A.; Ueda, M.; Hirano, Y.; Matsuzaki, R. 3D Printing of Continuous Carbon Fibre Reinforced Thermo-Plastic (CFRTP) Tensile Test Specimens. Open J. Compos. Mater. 2016, 6, 18-27. [CrossRef]

29. Pyl, L.; Kalteremidou, K.A.; Van Hemelrijck, D. Exploration of specimen geometry and tab configuration for tensile testing exploiting the potential of 3D printing freeform shape continuous carbon fibre-reinforced nylon matrix composites. Polym. Test. 2018, 71, 318-328. [CrossRef]

30. Yasa, E.; Ersoy, K. Dimensional Accuracy and Mechanical Properties of Chopped Carbon Reinforced Polymers Produced by Material Extrusion Additive Manufacturing. Materials 2019, 12, 3885. [CrossRef]

31. Yasa, E. Anisotropic impact toughnness of chopped carbon fiber reinforced nylon fabricated by material-extrusion-based additive manufacturing. Anadolu Univ. J. Sci. Technol. Appl. Sci. Eng. 2019, 20, 195-203. [CrossRef]

32. de Toro, E.V.; Sobrino, J.C.; Martínez, A.M.; Eguía, V.M.; Pérez, J.A. Investigation of a short carbon fibre-reinforced polyamide and comparison of two manufacturing processes: Fused Deposition Modelling (FDM) and polymer injection moulding (PIM). Materials 2020, 13, 672. [CrossRef] [PubMed]

33. Abdullah, A.M.; Mohamad, D.; Rahim, T.N.A.T.; Akil, H.M.; Rajion, Z.A. Effect of narrow infill density gap on the compressive properties of 3D printed carbon fibre reinforced acrylonitrile butadiene styrene. J. Mech. Sci. Technol. 2019, 33, 2339-2343. [CrossRef]

34. Mohammadizadeh, M.; Fidan, I.; Allen, M.; Imeri, A. Creep behavior analysis of additively manufactured fiber-reinforced components. Int. J. Adv. Manuf. Technol. 2018, 99, 1225-1234. [CrossRef]

35. Bakis, C.E.; Haluza, R.T.; Bartolai, J.; Kim, J.J.; Simpson, T.W. Assessment of anisotropic mechanical properties of a 3D printed carbon whisker reinforced composite. Adv. Compos. Mater. 2019, 28, 545-560. [CrossRef]

36. Tezel, T.; Kovan, V.; Topal, E.S. Effects of the printing parameters on short-term creep behaviors of three-dimensional printed polymers. J. Appl. Polym. Sci. 2019, 136, 6-11. [CrossRef]

37. Wang, K.; Li, S.; Rao, Y.; Wu, Y.; Peng, Y.; Yao, S.; Zhang, H.; Ahzi, S. Flexure behaviors of ABS-based composites containing carbon and Kevlar fibers by material extrusion 3D printing. Polymers 2019, 11, 1878. [CrossRef] [PubMed]

38. Durga Prasada Rao, V.; Rajiv, P.; Navya Geethika, V. Effect of fused deposition modelling (FDM) process parameters on tensile strength of carbon fibre PLA. Mater. Today Proc. 2019, 18, 2012-2018. [CrossRef]

39. Ding, Q.; Li, X.; Zhang, D.; Zhao, G.; Sun, Z. Anisotropy of poly(lactic acid)/carbon fiber composites prepared by fused deposition modeling. J. Appl. Polym. Sci. 2020, 137, 1-11. [CrossRef] 
40. Ivey, M.; Melenka, G.W.; Carey, J.P.; Ayranci, C. Characterizing short-fiber-reinforced composites produced using additive manufacturing. Adv. Manuf. Polym. Compos. Sci. 2017, 3, 81-91. [CrossRef]

41. Akasheh, F.; Aglan, H. Fracture toughness enhancement of carbon fiber-reinforced polymer composites utilizing additive manufacturing fabrication. J. Elastomers Plast. 2019, 51, 698-711. [CrossRef]

42. Ferreira, I.; Vale, D.; Machado, M.; Lino, J. Additive manufacturing of polyethylene terephthalate glycol /carbon fiber composites: An experimental study from filament to printed parts. Proc. Inst. Mech. Eng. Part L J. Mater. Des. Appl. 2019, 233, 1866-1878. [CrossRef]

43. Ghebretinsae, F.; Mikkelsen, O.; Akessa, A.D. Strength analysis of 3D printed carbon fibre reinforced thermoplastic using experimental and numerical methods. IOP Conf. Ser. Mater. Sci. Eng. 2019, 700. [CrossRef]

44. Giannakis, E.; Koidis, C.; Kyratsis, P.; Tzetzis, D. Static and fatigue properties of 3D printed continuous carbon fiber nylon composites. Int. J. Mod. Manuf. Technol. 2019, 11, 69-76.

45. Goh, G.D.; Dikshit, V.; Nagalingam, A.P.; Goh, G.L.; Agarwala, S.; Sing, S.L.; Wei, J.; Yeong, W.Y. Characterization of mechanical properties and fracture mode of additively manufactured carbon fiber and glass fiber reinforced thermoplastics. Mater. Des. 2018, 137, 79-89. [CrossRef]

46. Iragi, M.; Pascual-Gonzalez, C.; Esnaola, A.; Aurrekoetxea, J.; Lopes, C.S.; Aretxabaleta, L. Characterization of elastic and resistance behaviours of 3D printed continuous carbon fibre reinforced thermoplastics. In Proceedings of the ECCM 2018-18th European Conference on Composite Materials, Athens, Greece, 25-28 June 2018; pp. 24-28.

47. Jiang, D.; Smith, D.E. Anisotropic mechanical properties of oriented carbon fiber filled polymer composites produced with fused filament fabrication. Addit. Manuf. 2017, 18, 84-94. [CrossRef]

48. Justo, J.; Távara, L.; García-Guzmán, L.; París, F. Characterization of 3D printed long fibre reinforced composites. Compos. Struct. 2018, 185, 537-548. [CrossRef]

49. Mansour, M.; Tsongas, K.; Tzetzis, D.; Antoniadis, A. Mechanical and Dynamic Behavior of Fused Filament Fabrication 3D Printed Polyethylene Terephthalate Glycol Reinforced with Carbon Fibers. Polym.-Plast. Technol. Eng. 2018, 57, 1715-1725. [CrossRef]

50. Patterson, A.E.; Pereira, T.R.; Allison, J.T.; Messimer, S.L. IZOD impact properties of full-density fused deposition modeling polymer materials with respect to raster angle and print orientation. Proc. Inst. Mech. Eng. Part C J. Mech. Eng. Sci. 2019. [CrossRef]

51. Sanei, S.H.R.; Lash, Z.; Servey, J.; Gardone, F.; Nikhare, C.P. Mechanical properties of 3D printed fiber reinforced thermoplastic. ASME Int. Mech. Eng. Congr. Expo. Proc. 2019, 12. [CrossRef]

52. Croccolo, D.; De Agostinis, M.; Olmi, G. Experimental characterization and analytical modelling of the mechanical behaviour of fused deposition processed parts made of ABS-M30. Comput. Mater. Sci. 2013, 79, 506-518. [CrossRef]

53. Laureto, J.J.; Pearce, J.M. Anisotropic mechanical property variance between ASTM D638-14 type i and type iv fused filament fabricated specimens. Polym. Test. 2018, 68, 294-301. [CrossRef]

54. Farhang, L.; Fernlund, G. Void and porosity characterization of uncured and partially cured prepregs. J. Compos. Mater. 2016, 50, 937-948. [CrossRef]

55. Nikishkov, Y.; Airoldi, L.; Makeev, A. Measurement of voids in composites by X-ray Computed Tomography. Compos. Sci. Technol. 2013, 89, 89-97. [CrossRef]

56. Little, J.E.; Yuan, X.; Jones, M.I. Characterisation of voids in fibre reinforced composite materials. NDT E Int. 2012, 46, 122-127. [CrossRef]

57. Christensen, R.; Miyano, Y.; Nakada, M. The size dependence of tensile strength for brittle isotropic materials and carbon fiber composite materials. Compos. Sci. Technol. 2015, 106, 9-14. [CrossRef]

58. Sanei, S.H.R.; Fertig, R.S. Uncorrelated volume element for stochastic modeling of microstructures based on local fiber volume fraction variation. Compos. Sci. Technol. 2015, 117, 191-198. [CrossRef]

59. Sanei, S.H.R.; Barsotti, E.J.; Leonhardt, D.; Fertig, R.S. Characterization, synthetic generation, and statistical equivalence of composite microstructures. J. Compos. Mater. 2017, 51, 1817-1829. [CrossRef]

60. Kregers, A.F.; Zilauts, A.F. Limiting values of reinforcement factors for fibrous composites with a three-dimensional structure. Mech. Compos. Mater. 1985, 20, 530-536. [CrossRef]

61. Kregers, A.F.; Teters, G.A. Determination of the elastoplastic properties of spatially reinforced composites by the averaging method. Mech. Compos. Mater. 1981, 17, 25-31. [CrossRef] 
62. Kreger, A.F.; Teters, G.A. Use of averaging methods to determine the viscoelastic properties of spatially reinforced composites. Mech. Compos. Mater. 1980, 15, 377-383. [CrossRef]

63. Christensen, R.M. Effective properties of composite materials containing voids. Proc. R. Soc. Lond. Ser. A Math. Phys. Sci. 1993, 440, 461-473. [CrossRef]

64. Hu, C.; Sun, Z.; Xiao, Y.; Qin, Q. Recent Patents in Additive Manufacturing of Continuous Fiber Reinforced Composites. Recent. Patents Mech. Eng. 2019, 12, 25-36. [CrossRef] 